\title{
Exploring International Differences in Inflation Dynamics
}

\author{
By \\ Yamin Ahmad \\ and \\ Olena Mykhaylova
}

July 2015

\section{COLLEGE OF THE HOLY CROSS, DEPARTMENT OF ECONOMICS FACULTY RESEARCH SERIES, PAPER NO. 15-09*}

\author{
Department of Economics \\ College of the Holy Cross \\ Box 45A \\ Worcester, Massachusetts 01610 \\ (508) 793-3362 (phone) \\ (508) 793-3710 (fax)
}

http://www.holycross.edu/academics/programs/economics-and-accounting

*All papers in the Holy Cross Working Paper Series should be considered draft versions subject to future revision. Comments and suggestions are welcome. 


\title{
Exploring International Differences in Inflation Dynamics*
}

\author{
Yamin Ahmad $^{\dagger}$ \\ Olena Mykhaylova $a^{\ddagger}$ \\ University of Wisconsin - Whitewater \\ College of the Holy Cross
}

July 18, 2015

\begin{abstract}
Standard closed-economy DSGE models have difficulty replicating the persistence of inflation. We use a multicountry dataset to establish some empirical regularities on persistence and volatility of aggregate consumer prices for 161 countries. We find persistence to be high (low) on average for developed (developing) countries, while volatility is low (high) on average for the same country groupings. We then employ a two-country DSGE framework to investigate the extent to which structural open economy features, such as incomplete exchange rate pass-through, the existence of nontraded goods, and international financial market incompleteness, can help in replicating the persistence and volatility of consumer prices. Our simulation results indicate that nominal price inertia in both wholesale and retail sectors has the potential to reconcile both the persistence and volatility of simulated inflation series with the data. When we simulate inflation series in the version of the model calibrated to a developingdeveloped country pair by allowing for different price contract durations and export currency choices, we are able to replicate the empirical differences reported in the first part of the paper.
\end{abstract}

JEL Classification: E31 F41 C22

Keywords: Inflation dynamics, persistence, volatility, DSGE modeling, simulations

\footnotetext{
* We would like to thank Jonathan Heathcote, Matt Canzoneri, Ivan Paya, Jeremy Piger, Jun Ma, James Murray and session participants at the Georgetown Center for Economic Research 2015 conference and Midwest Applied Time Series and Econometrics Group 2014 conference for valuable comments and suggestions. All remaining errors are our own.

${ }^{\dagger}$ Corresponding author. Department of Economics, 800 W Main Street, Whitewater, WI 53190. Email: ahmady@uww.edu. Homepage: http://facstaff.uww.edu/ahmady/ Tel: (262) 4725576

$\ddagger$ Department of Economics, Box 45A, College of the Holy Cross, One College Street, Worcester, MA $01610 . \quad$ Email: omykhayl@holycross.edu
} 


\section{Introduction}

The question of whether the dynamics of inflation within a country is characterized by structural persistence is seemingly simple, yet the answer to it is of great importance for the design of macroeconomic models and for the implementation of optimal monetary policy. A central question that arises in examining the behavior of households, firms, and other economic agents is whether they systematically utilize past information in setting prices and reacting to changes in the price level, or whether the dynamics of inflation is dominated by expectations and the purely forward-looking behavior of these agents. Although a large literature has emerged that examines this issue in a closed economy context, it may be missing several important mechanisms driving the behavior of inflation given the multitude of international linkages that exist between countries today, a gap we aim to fill in this paper.

While there is no unique definition of persistence, in the literature this term has been used to refer to the time it takes for the effects of a shock hitting the economy to die out. In this sense, future values of a particular variable depend on the realization of prior shocks that hit the economy. Hence the term "inflation persistence" encapsulates a measure of the time it would take for the rate of inflation to return to its long-run value after being perturbed as a result of a shock. From a policy perspective, knowing the degree of inflation persistence is important, if only to determine the appropriate response to various shocks. If the degree of inflation persistence were small, then a shock to the inflation rate would die out quickly and thus potentially rule out a need for monetary policy intervention. On the other hand, for countries with a greater degree of inflation persistence, monetary policy might have a more significant role to play in stabilizing the price level. Moreover, if inflation persistence is a structural feature of an economy, as has been intimated in some previous studies, the standard Taylor rule prescription for monetary policy conduct may be sub-optimal.

In an influential paper, Fuhrer and Moore (1995) advocated for the need to "hardwire" inflation persistence 
into the models used for policy analysis. The authors found that macroeconomic models of the time were unable to generate the same degree of inflation persistence observed in the data, prompting a number of researchers to look for new ways to "fix" the theoretical framework, sometimes in ad-hoc ways, in order to bring the moments of inflation closer to their empirical counterparts 1 The ensuing work on inflation persistence primarily examined the issue in a closed economy setting, focusing on the key equation governing the evolution of inflation — the New Keynesian Phillips Curve (NKPC) — and modified it several (non-exclusive) ways. For example, Galí and Gertler (1999), Steinsson (2003), and Christiano, Eichenbaum and Evans (2005), among many others, allowed the price-setting firms in their models to index a fraction of their prices to past inflation, thus adding a backward-looking component to the NKPC. Papers such as Lindé, Nessén, and Söderström (2009) and Rhee and Turdaliev (2012) added habit formation to the consumer utility function to increase the degree of persistence of real variables, which would subsequently add sluggishness to the behavior of prices.

Yet not all researchers saw the need to model structural inflation persistence; several papers found evidence suggesting that empirical persistence was much lower than previously thought. More specifically, Benati (2008) examined a number of developed countries and found the indexation parameter to be low (or zero) for the hybrid NKPC. Cogley and Sbordonne (2008) went on to suggest that inflation may be purely forward looking, once trend inflation is accounted for. Levin and Piger (2006), using a sample of several industrialized countries, reported that high inflation persistence was not as inherent in the data once structural breaks were accounted for. In follow-up empirical investigations, some studies have suggested that inflation persistence may have declined (for example, Cogley and Sargent, 2005 and Cogley, Primiceri, and Sargent, 2010), while others, such as Sims (2002) and Pivetta and Reis (2007), find that it may have remained unchanged, the latter using a Bayesian approach. Given the conflicting evidence on both

\footnotetext{
${ }^{1}$ Mechanically, a high degree of inflation persistence can be generated by assuming very infrequent price reoptimization on the part of producers; however, the degree of nominal inertia necessary to match the empirical moments of inflation was found to be much higher than suggested by microeconomic evidence (see, for example, Christiano, Eichenbaum and Evans, 2005, and the empirical findings in Bils and Klenow, 2004).
} 
theoretical and empirical sides of the debate, the question of inflation persistence continues to sustain a lively discussion in the literature.

We contribute to this debate by considering the theoretical channels that affect inflation dynamics in an open-economy setting, which we believe to be an important area to examine given the ever-growing interconnectedness among the world's economies. To keep our focus squarely on the relationship between inflation and international variables (such as exchange rates and cross-country price-setting contracts), we abstract from the issues such as the need for a backward-looking component in the Phillips curve, whether inflation persistence has increased or decreased over time, and the extent to which monetary policy itself may impact the degree of inflation persistence. Although clearly relevant to our work, these questions have been examined in great detail in other studies, including the ones mentioned earlier. Our approach is different from the existing papers that examine the NKPC in the open-economy setting, such as Lindé, Nessén, and Söderström (2009), Kuralbayeva (2011), and Rhee and Turdaliev (2012); while these authors do consider the interaction between the real exchange rate and domestic inflation, the papers do not explicitly analyze the change in inflation behavior due to various features of open economies. Moreover, they continue to model backward-looking price indexation, which has proven difficult to justify from the microeconomic perspective.

Our contribution is threefold. We begin with an exploration of a large international dataset to establish any empirical regularities that may exist with regards to inflation persistence and volatility. The majority of papers that have examined the issue of inflation persistence to date have primarily focused on industrialized countries. We take a much broader approach and examine consumer prices from 161 countries, including both developed and developing economies; additionally, we also examine inflation persistence in the G20 countries and the European Union as a whole. To our knowledge, ours is the first paper to consider the importance of different groupings. Contrary to what conventional wisdom may indicate, we find inflation 
persistence to be higher in developed countries relative to the entire sample average; conversely, persistence is much lower in our subset of developing economies. The opposite is true for inflation volatility: it is lower (as may be expected) in developed countries than in the developing world.

Second, we revisit the broader question of whether inflation persistence is a "structural" phenomenon by employing a two-country DSGE model with a variety of structural features that impact international price dynamics. Setting aside the issue of whether inflation persistence should be "hardwired" into theoretical models, we ask which, if any, open-economy structural features influence inflation persistence and volatility. We derive several open-economy extensions of the NKPC that include (one at a time) home bias in consumption, deviations from the Law of One Price, departures from Uncovered Interest Parity (UIP) due to incomplete international financial markets, and nontraded goods. Aside from adding another price process (of the imported goods) to the consumer basket, the open economy framework changes inflation dynamics through the behavior of the nominal exchange rate. Ahmad, Lo, and Mykhaylova (2013a, b) have demonstrated that the properties of the exchange rate series differ quite significantly across various open economy specifications. Here we take these findings one step further by studying the resulting moments of aggregate consumer prices.

We find, somewhat surprisingly, that introducing these features to the model does not significantly affect the resulting inflation persistence. On the other hand, we can significantly improve the model's fit visà-vis the (developed country) data by differentiating between the wholesale and retail sectors, a feature frequently used in the literature to explain the difference in the degree of exchange rate pass-through into import versus consumer prices. Intuitively, having two sectors that are both subject to nominal rigidities allows us to insulate consumer prices from the underlying economic disturbances. Thus, we improve on the results reported in, among others, Christiano, Eichenbaum and Evans (2005) by showing that the commonly assumed levels of price stickiness (of three to four quarters), combined with the layering of wholesale and 
retail firms, are enough to bring the simulated inflation inertia close to its empirical counterpart.

Finally, we use our findings to address the reported differences in inflation dynamics between developed and developing economies. The decisions of exporting firms as to the choice of invoicing currency and the frequency of price re-optimization vary significantly depending on the destination markets. Firms exporting to stable low-inflation (developed) countries typically choose to invoice their goods in foreign currency and leave prices unchanged for relatively long periods of time - up to a year. Prices of exports destined for more volatile and high-inflation (developing) markets are, on the other hand, denominated in the currency of the exporter and reset much more frequently - once a quarter or more. When we simulate inflation series in the asymmetric version of the model by allowing for different price contract durations and export currency choices, we are able to replicate the empirical differences between developed and developing economies reported in the first part of the paper.

Of course, the pricing decisions of firms, the stability of economic environment, and the conduct of monetary policy evolve endogenously. However, insofar as it is important to understand the impact on inflation dynamics of each of these features separately, we show that, holding the central bank policy rules constant, the structure of international price contracts can explain most of the differences in inflation volatility and persistence we observe in the data. Nonetheless, it is important to emphasize that the focus of the paper remains strictly a positive one; we leave the exploration of the normative implications of our findings for the conduct of monetary policy to future research.

The remainder of the paper is structured as follows. The next section presents and discusses empirical regularities pertaining to inflation persistence and volatility in international data. We then outline the twocountry framework and describe the links between its open economy features and the resulting inflation dynamics. We proceed to report our findings from the model simulations - both baseline and calibrated to a developing-developed country pair - and finally offer some concluding remarks and suggestions for future 
research.

\section{Patterns in the international data}

Before embarking on a study of the theoretical links between openness and inflation dynamics, we explore the patterns in inflation persistence and volatility using a dataset of 161 countries during the 1970Q12013Q1 period. In particular, we wish to establish any empirical regularities in the data that pertain to both persistence and volatility. We calculate inflation simply as the quarter-on-quarter percentage change in the consumer price level, and measure volatility as the standard deviation of the resulting series.2

\subsection{Inflation Persistence}

As we noted earlier, there is no universally accepted measure of inflation persistence that is utilized by all studies. A common approach to obtaining a measure of persistence is to estimate a time series model, which is often an autoregressive process. While a number of studies compute impulse response functions in order to examine the persistence of a time series, others use the estimated time series model to compute a scalar measure of persistence, since the usefulness of an impulse response function, represented as an infinite-length vector, is limited when quantifying and comparing persistence across different time series. Hence, scalar measures are often used as a summary statistic since they typically summarize the information contained within the impulse response function. As noted by Dias and Marques (2010), the most popular measure in the literature that examines inflation persistence is the sum of the autoregressive coefficients, which is a monotonic transformation of the cumulative impulse response function; hence, below we use this measure to describe inflation persistence in our sample 3

\footnotetext{
${ }^{2}$ The data comes from IMF's International Financial Statistics, series name: Consumer Prices, All Items (64...ZF). The series start in the first quarter of 1970 or the earliest available date.

${ }^{3}$ Other scalar measures include the half-life, the largest autoregressive root (see Stock, 1991, 2001), the absence of mean reversion (Marques, 2004), and the zero frequency spectrum (Andrews and Chen, 1994). We refer the interested reader to
} 
We assume that the dynamics of inflation, $\pi_{t}$, may be succinctly described by a univariate autoregressive process of the form

$$
\pi_{t}=\lambda_{0}+\sum_{i=1}^{p} \lambda_{i} \pi_{t-i}+\varepsilon_{t}
$$

where $\pi_{t}=p_{t}-p_{t-1}$ is the change in the log price and $\varepsilon_{t}$ is a white noise process. This series is stationary if the sum of the autoregressive coefficients, $\sum_{i=1}^{p} \lambda_{i} \equiv \Lambda$, is less than one in absolute value. In equation (1) above, the dynamics of inflation are governed by the key parameters $\left\{\lambda_{1}, \ldots, \lambda_{p}\right\}$, and $\Lambda$ represents our measure of persistence. When fitting equation (1) to the data, we allow the data to select the order of autoregression, $p$, using the Schwartz-Bayes Criterion (SBC), which is known to favor a parsimonious representation of the data generating process, although we limit the maximum autoregressive order to equal 12 (or, equivalently, 3 years).

The properties of the data are summarized in Figure 1 and Table1. In Figure1, we see that the distribution of estimated persistence is fairly spread out across all the countries, although it is skewed to the left. The majority of countries exhibit positive persistence. When looking at the distribution of volatilities, we note that it is much tighter than that for persistence, particularly once the twelve countries with the highest volatilities - Angola, Armenia, Argentina, Bolivia, Brazil, Bulgaria, DR Congo, Croatia, Georgia, Kazakhstan, Peru and Ukraine - have been excluded. The only true outlier amongst these countries is Croatia, whose volatility of 4.31 is far higher than the others, which range from 0.32 to 1.14 .

In addition to studying the full sample, we also separate the countries into several subcategories based on their level of development. We use the country classification from the IMF's World Economic Outlook 2012 to group countries into developing and developed categories 4 We also consider the G20 group of

Paya, Duarte and Holden (2007) and Dias and Marques (2010), who discuss the advantages and disadvantages of various scalar measures relative to the information contained in an impulse response function.

${ }^{4}$ To ensure that the findings are robust, we recalculate the averages of the two moments of inflation using the country classification provided by the World Bank World Development Report (we classify high income countries as developed and the rest as developing). Additionally, we also change the date of both classifications to 1992, coinciding with the middle of our sample. The results, which remain virtually unchanged, are available from the authors upon request. 

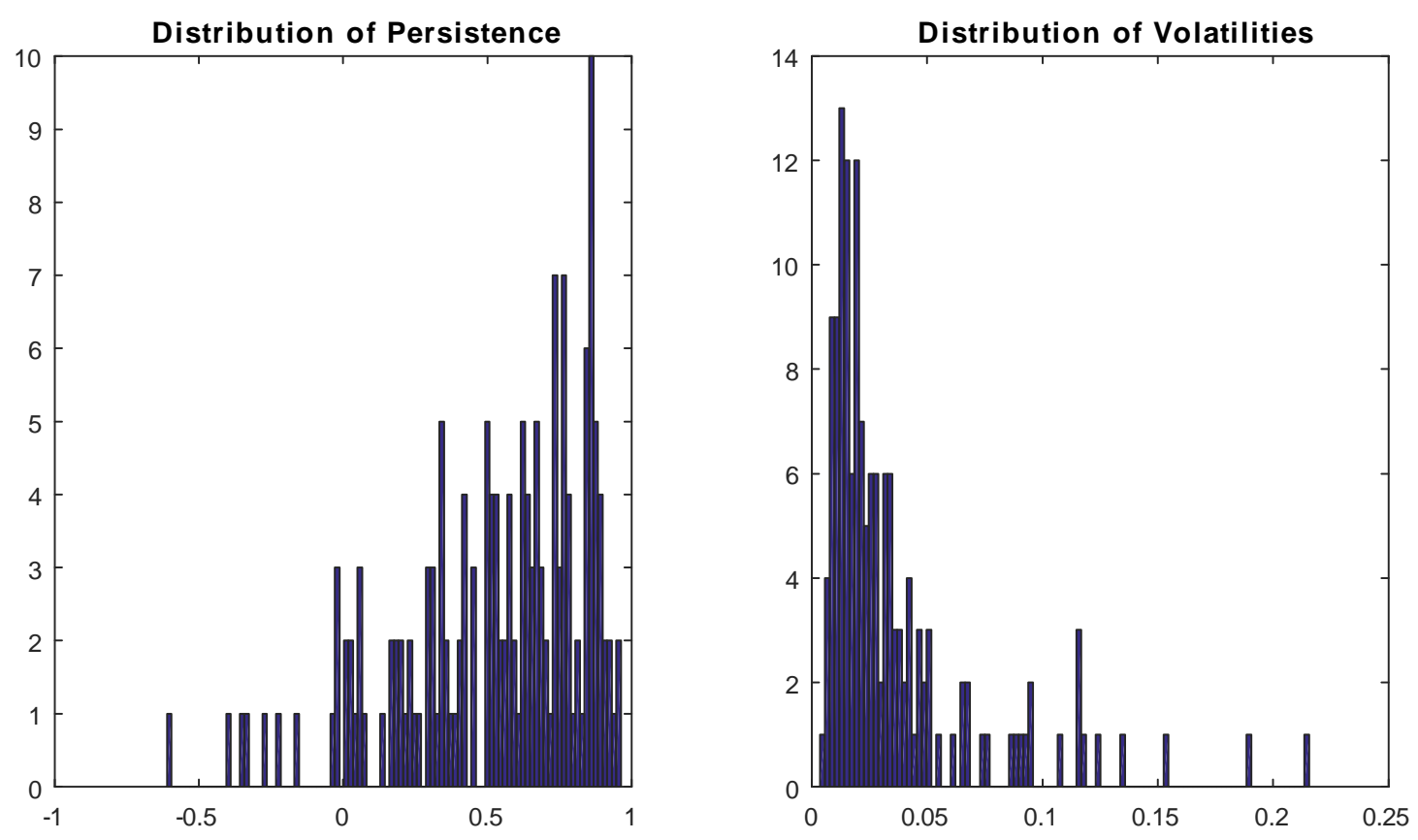

Figure 1: Distributions of estimated persistence and volatilities across the countries. Note: the volatilities depicted in the right panel exclude twelve countries with the highest volatilities, which include Angola, Argentina, Armenia, Bolivia, Brazil, Bulgaria, DR Congo, Croatia, Georgia, Kazakhstan, Peru, Ukraine. 
countries, excluding the European Union (EU), which we treat separately $!^{5}$ Our choice of this subsample is motivated by the observation that the G20 group comprises 85 percent of the world's GDP, accounts for two thirds of its population, and is responsible for 75 percent of global trade. The EU is an interesting group to consider as well, given that it includes countries at various stages of development, the majority of which are in the European Monetary Union.

\begin{tabular}{|c|c|c|c|c|c|c|c|c|}
\hline Countries & $\mathrm{n}$ & Min & $\operatorname{Max}$ & Median & Mean & M50 & M5 & M95 \\
\hline \multicolumn{9}{|c|}{ Panel A: Persistence } \\
\hline Full sample & 161 & -0.611 & 0.963 & 0.600 & 0.527 & 0.637 & 0.464 & 0.819 \\
\hline Developing & 128 & -0.611 & 0.963 & 0.513 & 0.456 & 0.548 & 0.383 & 0.745 \\
\hline Developed & 33 & 0.130 & 0.955 & 0.866 & 0.802 & 0.918 & 0.794 & 1.041 \\
\hline G20 & 19 & 0.293 & 0.945 & 0.793 & 0.756 & 0.865 & 0.708 & 0.997 \\
\hline European Union & 28 & 0.210 & 0.955 & 0.866 & 0.771 & 0.910 & 0.785 & 1.041 \\
\hline \multicolumn{9}{|c|}{ Panel B: Volatility } \\
\hline Full sample & 161 & 0.005 & 4.306 & 0.026 & 0.100 & & & \\
\hline Developing & 128 & 0.007 & 4.306 & 0.031 & 0.121 & & & \\
\hline Developed & 33 & 0.005 & 0.117 & 0.012 & 0.019 & & & \\
\hline G20 & 19 & 0.006 & 0.557 & 0.019 & 0.086 & & & \\
\hline European Union & 28 & 0.006 & 0.424 & 0.015 & 0.052 & & & \\
\hline
\end{tabular}

Table 1: Estimates of inflation persistence and volatility for country groupings across the world. Data consists of inflation computed from quarter-on-quarter percentage change in the consumer price index. Notes:

(i) M50 represents the median of the median (50th percentile) unbiased estimates of the persistence parameter across the countries in each grouping; similarly, M5 and M95 represent the medians of the 5th and 95th percentiles of the distributions across the country groupings.

(ii) The median unbiased estimates and the 5th and 95th percentiles are computed via Hansen's (1999) grid bootstrap method to simulate the sampling distribution of the t-statistic over a grid of possible values for $\Lambda$. We use a grid consisting of 200 points, and bootstrap using 1000 replications.

The results in panel A of Table 1 show that for the full sample of countries, the median estimate of persistence is 0.6. A useful way to interpret this number is to note that if the dynamics of inflation were characterized by an $\mathrm{AR}(1)$ process, then this persistence parameter would yield a half-life of approximately 1.36 quarters (or just over 4 months) $\stackrel{6}{6}^{6}$ As such, this would indicate that, on average, inflation persistence

\footnotetext{
${ }^{5}$ The European Union is currently made up of 28 countries. Although it consists of both high income and middle-low income countries, it is treated as a single entity within the G20.

${ }^{6}$ The half-life for an $\operatorname{AR}(1)$ process given by $q_{t}=\lambda_{1} q_{t-1}+\varepsilon_{t}$ can be calculated as $\frac{\ln 0.5}{\ln \lambda}$. For an autoregressive process of order $p$, there is no simple expression for the half-life, although Andrews and Chen (1994) suggest computing the half-life
} 
is relatively low across countries. However, after inspecting the estimates for the developed countries subsample, we find a substantially higher degree of persistence: $\Lambda=0.866$, equivalent to the half-life of approximately 4.82 quarters, or just under 15 months. When only considering developing countries, we find the degree of persistence to be smaller, $\Lambda=0.513$, corresponding to a half-life of 3 months.

Two other points merit particular attention when considering these estimates of persistence. First, it is well known in the literature that the least squares estimates of the persistence parameter are biased downwards, particularly as the persistence parameter gets larger (see Andrews, 1993 and Andrews and Chen, 1994). For this reason, we use Hansen's (1999) grid bootstrap method to calculate and report the median unbiased estimate (MUE) of the persistence parameter, as well as its $90 \%$ confidence sets. The results show that the average of the MUEs for the persistence parameter are higher than their unadjusted counterparts. For developing countries, the increase is marginal. However, for developed countries, the persistence parameter increases on average from 0.866 to 0.92 , which represents an approximate increase in the half-life of more than ten months. Furthermore, when looking at the $90 \%$ confidence sets, we find them to be non-overlapping for developing and developed countries. The confidence sets for the developing countries translate into a range of the half-life from 2 to 7 months, indicating a lack of persistence that we observe in developed countries. For developed countries, the confidence set suggests a lower bound for the half-life of approximately 9 months. The upper bound for the coverage of the confidence sets is greater than one for developed countries, thereby including a unit-root inflation process.

Second, it is also well documented that the presence of structural breaks in the time series can affect the estimate of persistence (Perron, 1990). For example, Levin and Piger (2006) allow for a structural break in the mean of the inflation series and show that the estimates of persistence for the majority of the industrialized countries that they examine are much lower than previously reported. While the results in Table 1 do not account for structural breaks in the data, we readily acknowledge this point and note using the sum of the autoregressive coefficients, $\Lambda$, instead of the $\operatorname{AR}(1)$ term, i.e. $\frac{\ln 0.5}{\ln \Lambda}$. 
that the focus of this paper is subtly different. In Levin and Piger (2006) and others, the authors aim to approximate the true measure of persistence for a particular country over time. As such, allowing for structural breaks in inflation is of great importance in order to account for changes in monetary policy. However, our goal is to estimate the patterns of inflation persistence across countries. Our intention is then to use these estimates to help identify the particular structural features of open economies that can explain differences in inflation persistence around the world. Consequently, it is not desirable to conduct tests of structural breaks for the countries in our sample. First, the data for many developing countries start in the late 1990's or early 2000's and thus do not include some of the significant events that happened on the world stage during the 1970's and 1980's; additionally, the small sample size makes it infeasible to perform structural break tests for these economies.

Moreover, it is not obvious how to use multiple estimates of persistence for a particular country to calculate a parsimonious statistic that would be readily comparable across countries, nor that such a statistic would be useful if the timing of breakpoints varies in different countries. À priori, it is not clear whether a weighted average of persistence measures across structural breaks, or some such other measure, would be more representative of the underlying inflation dynamics than an 'unconditional' measure that does not account for the presence of breaks in the data. Although the estimates of persistence are likely biased upwards in the latter case, it is our hope that applying the same methodology to all economies will mitigate the effects of any bias as the sample size (of countries) grows, particularly since we are interested in understanding factors that contribute towards relative persistence across countries.

Therefore, in the spirit of obtaining an 'unconditional' measure of persistence in our cross-country sample, we proceed with the median estimates reported in Table 1 as a benchmark by which to analyze the theoretical results in the later sections. Overall, we take the empirical results here to be indicative of persistent inflation dynamics across our sample of countries as a whole. 
When considering the inflation volatility reported in panel B of Table (1), we find a much tighter distribution of the estimated parameter, with the average of the standard deviation of the inflation series across countries amounting to only $2.6 \%$. In addition, we find that the median volatility across the sample is higher for developing countries and lower for the more advanced economies.
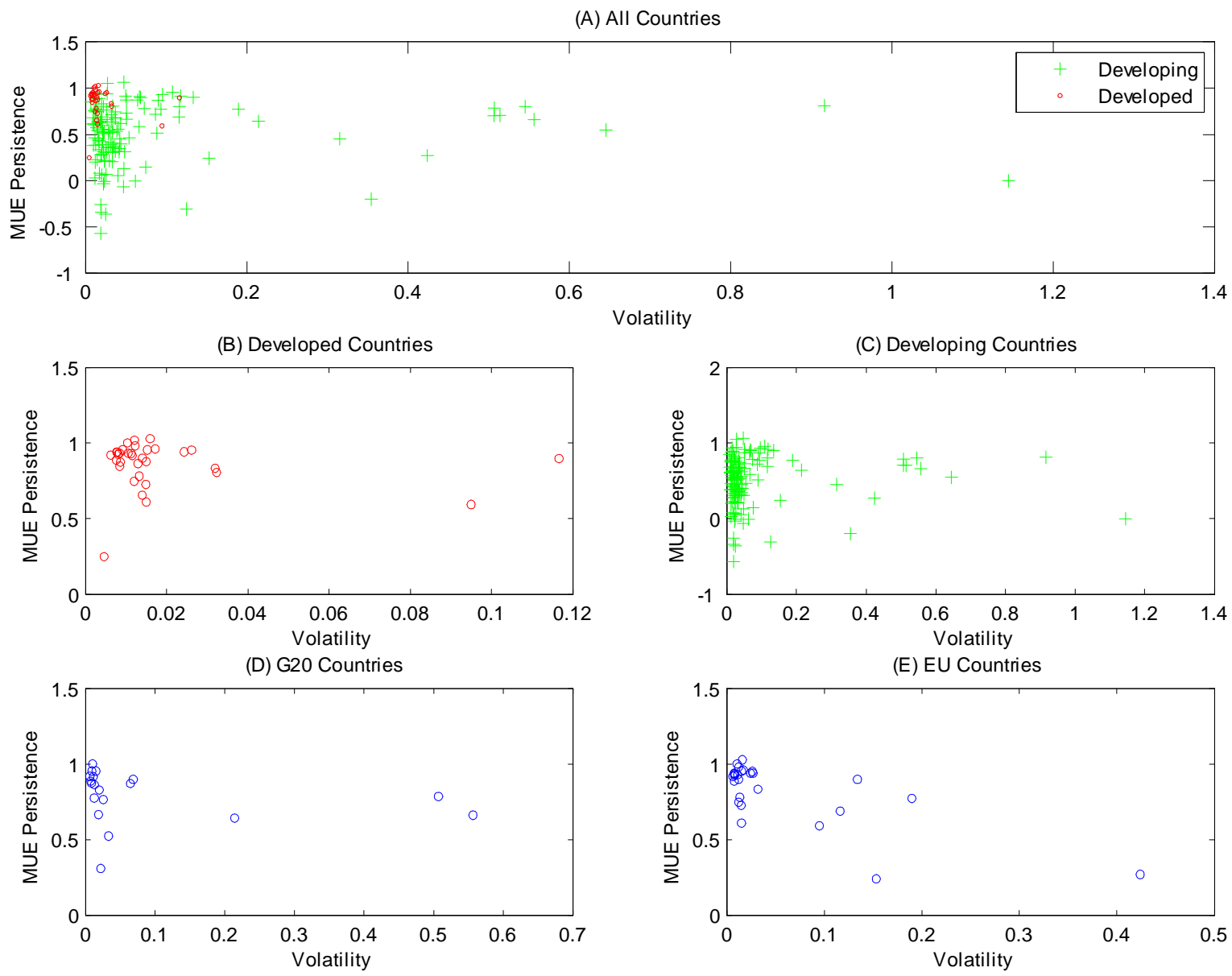

Figure 2: Median unbiased estimates of persistence and volatility across country groupings. Data reported above exclude Croatia.

The key differences between these country groupings are illustrated in Figure 2, Panel (A) shows that developed countries are grouped on the whole in the top left corner of the graph: they are characterized by higher values of inflation persistence relative to developing countries, as well as lower levels of inflation 
volatility. Panels (B) and (C) separate the countries into the developed and developing subsamples. While there is some difference in inflation moments within the two groups, we see that the level of dispersion for persistence and volatility is much larger in absolute value for developing countries. Overall, the pattern of results above paints an interesting picture of inflation dynamics around the world. Based on these findings, we identify two empirical regularities in our data:

1. Developing countries tend to have higher volatility and lower inflation persistence relative to all the countries in the sample.

2. Developed countries tend to have lower volatility and higher persistence as compared to all the countries in the sample.

A valid interpretation of the results presented in Table 1 could attribute the differences in inflation dynamics between developing and developed economies to the differences in the stance of monetary policy. For example, the more inertial inflation-targeting rules pursued by central banks in developed economies may result in lower volatility and greater persistence of their inflations (Taylor, 2000; Devereux and Yetman, 2010). Alternatively, the high estimate of persistence in the developed world may be capturing the nonlinear approach to inflation targeting (studied in, among others, Orphanides and Wilcox, 2002; Aksoy et al. 2006; Kilian and Manganelli, 2007 and 2008; and Nobay et al., 2010). In models that support such nonlinear behavior, inflation is allowed to drift within a target band (resulting in high persistence) but is brought back to the band after experiencing a particularly large shock. Arguably, developing countries do not have the institutional credibility to implement such policy as effectively as developed countries, resulting in higher volatility and lower persistence. It has also been noted that the total factor productivity processes of developing and developed countries possess very different properties (see, for example, Aguiar and Gopinath, 2007). A less volatile and more persistent path of the Solow residual in developed economies may pass these properties onto the inflation process. 
While monetary policy and technology can in fact account for a portion of the differences in Table 1, we want to understand whether these data patterns can be explained by appealing to the differences in the open economy features of the countries in our dataset, such as home bias in consumption or local currency pricing. It is very likely that monetary policy rules and open economy features do not evolve independently of each other; however, it is informative to disentangle the marginal effects of the structural and policy characteristics of different countries on the resulting on inflation dynamics. To do so, we next employ a two-country DSGE model in which both economies have the same monetary policy function but differ in the way they are linked to international markets.

\section{The open economy DSGE framework}

The benchmark model is composed of two countries, Home $(H)$ and Foreign $(F)$, each populated by infinitely lived households of measure $M$ at home and $M^{*}$ abroad; there is no migration. The two economies have a similar structure but differ in several parameter values; therefore, below we focus on the home country equations. Households consume a combination of home and foreign goods, and international asset markets are complete. As a matter of notation, subscripts $H$ and $F$ will refer to a good's country of origin; asterisks will indicate that it is consumed in country $F$. The full model, its equilibrium conditions, and the solutions to the agents' problems are outlined in Ahmad, Lo, and Mykhaylova (2013a); therefore, below we keep our description of them brief.

\subsection{Benchmark setup}

Each country has a continuum of firms that produce tradable goods indexed by $f$ on the unit interval. At time $t$, each home firm rents capital $K_{T, t-1}(f)$ from the domestic households at the rate $R_{t}$, hires labor 
$L_{T, t}(f)$ at the rate $W_{t}$, and produces one of the varieties of the domestic good according to

$$
Y_{H, t}(f)=M\left[K_{T, t-1}(f)\right]^{\nu}\left[Z_{T, t} L_{T, t}(f)\right]^{1-\nu}
$$

where $0<\nu<1$, and $Z_{T, t}$ denotes the level of productivity enjoyed by all tradable home firms at time $t$. We use the subscript $T$ to differentiate between tradable and nontradable goods (introduced in Section 3.2). All goods varieties are then bundled into a composite home good using the Dixit-Stiglitz aggregator:

$$
Y_{H, t}=\left\{\int_{0}^{1}\left[Y_{H, t}(f)\right]^{\frac{\sigma_{T, t}-1}{\sigma_{T, t}}} d f\right\}^{\frac{\sigma_{T, t}}{\sigma_{T, t^{-1}}}}
$$

where $\sigma_{T, t}>1$ is the time-varying price markup. This composite good can be used for public and private consumption or private investment. As in Calvo (1983), firms reset their prices each period with a constant probability $(1-\alpha)$; otherwise, the old prices remain in effect. If a firm $f$ gets to announce a new price in period $t$, it chooses $\tilde{P}_{H, t}(f)$ to maximize its expected discounted future profits.

The representative household derives utility from consumption and leisure; consumption $C_{T, t}$ is aggregated from the home and foreign intermediate goods according to

$$
C_{T, t}=\left[\mu^{\frac{1}{\sigma_{H F}}}\left[C_{H, t}\right]^{\frac{\sigma_{H F}-1}{\sigma_{H F}}}+(1-\mu)^{\frac{1}{\sigma_{H F}}}\left[C_{F, t}\right]^{\frac{\sigma_{H F}-1}{\sigma_{H F}}}\right]^{\frac{\sigma_{H F}}{\sigma_{H F}-1}},
$$

where $\sigma_{H F}$ measures the elasticity of substitution between home and foreign goods, and $\mu$ captures the degree of home bias in consumption. Since the law of one price (LOOP) holds in this specification, the prices of the two final goods, which also represent the countries' CPIs, are given by

$$
\begin{aligned}
P_{T, t} & =\left[\mu P_{H, t}^{1-\sigma_{H F}}+(1-\mu) S_{t} P_{F, t}^{*}\left(1-\sigma_{H F}\right)\right]^{\frac{1}{1-\sigma_{H F}}} \\
P_{T, t}^{*} & =\left[\mu^{*} P_{F, t}^{*\left(1-\sigma_{H F}\right)}+\left(1-\mu^{*}\right) S_{t}^{-1} P_{H, t}^{\left(1-\sigma_{H F}\right)}\right]^{\frac{1}{1-\sigma_{H F}}}
\end{aligned}
$$

Here $S_{t}$ is the nominal exchange rate, expressed in units of Home currency per one unit of Foreign currency. We define the real exchange rate $(\mathrm{RER})$ as $Q_{t} \equiv S_{t} P_{T, t}^{*} / P_{T, t}$. Notice that the only potential source of 
real exchange rate fluctuations in the benchmark model is price rigidity. Households in both countries have access to a complete contingent claims market. Capital stock evolves over time in accordance with household investment decisions.

The Home monetary policy is a variant of the Taylor rule, in which the short-term nominal interest rate responds (with inertia) to deviations of inflation and output from their targets:

$$
i_{t}=\left(1-\rho_{i}\right) \bar{i}+\rho_{i} i_{t-1}+\left(1-\rho_{i}\right)\left[\rho_{\pi} \pi_{t}+\rho_{y} y_{t}^{g a p}\right]+\varepsilon_{i, t}
$$

Here $\bar{i}=$ is the steady state level of the interest rate, $\pi_{t}$ is the growth rate of CPI, and $y_{t}^{g a p}$ denotes output gap, which we measure as the deviation of output from its steady state level. The specific target of the central bank —inflation, exchange rate, or a combination of both-will produce different effects on inflation dynamics. Open economies often engage in policies to stabilize their exchange rates, an issue examined in great detail in the literature emerging from findings in, among others, Cole and Obstfeld (1991), Obstfeld and Rogoff (1995), and Calvo and Reinhart (2002). We, however, focus on the closed-economy version of the Taylor rule since we want to understand, ceteris paribus, the impact of structural open-economy features on inflation dynamics.

Government consumption is described by an autoregressive process

$$
\ln G_{T, t}=\left(1-\rho_{g}\right) \ln \overline{G_{T}}+\rho_{g} \ln G_{T, t-1}+\varepsilon_{g, t},
$$

where $\varepsilon_{g, t}$ is a white noise process, and $\overline{G_{T}}$ denotes the steady state level of government spending. Both governments balance their budgets every period.

\subsection{Extensions}

The benchmark specification, in which Purchasing Power Parity (PPP) holds at all times, generates virtually no real exchange rate movement and therefore serves as a stepping stone to richer frameworks with 
more frictions in international prices. In the presence of nominal rigidities, real exchange rate dynamics directly impacts the degree of exchange rate pass-through into import and consumer prices and thus can significantly affect the moments of inflation. Below we outline four widely used extensions of the basic DSGE model that break the absolute PPP or the UIP relationships and thus introduce richer exchange rate dynamics. We add them one at a time, and also examine several combinations of the extensions in our simulations. In what follows below, lowercase letters denote log deviations from the steady state unless otherwise stated.

1. Home bias in consumption. The existence of home bias in consumption has been well documented in the trade literature (for example, in Obstfeld and Rogoff, 2000); to introduce it into our model, we require that $\mu+\mu^{*} \neq 1$. To see the impact of this assumption on the RER dynamics, we substitute (3) into the definition of the real exchange rate and linearize around the symmetric steady state to obtain

$$
q_{t}=\left[\mu^{*}+\mu-1\right] \tau_{t}
$$

where $\tau_{t} \equiv p_{F, t}^{*}+s_{t}-p_{H, t}$ represents the terms of trade. As the economies move away from the symmetric case $\left(\mu=\mu^{*}=0.5\right.$ or, more generally, $\left.\mu=1-\mu^{*}\right)$, real exchange rate movements grow in magnitude in response to fluctuations in the terms of trade.

2. Local currency pricing (LCP). Empirical evidence points to a rather low degree of pass-through from exchange rates to import prices, which of course is inconsistent with our benchmark assumption that the LOOP holds in the individual, as well as the aggregate price level $]^{7}$ The literature has identified several potential causes of this phenomenon: local currency pricing by firms with some degree of monopoly power, the presence of nontraded goods either in the product distribution network or

\footnotetext{
${ }^{7}$ For example, Engel (1993) finds empirical evidence that the volatility of the price of a good relative to a similar good within a country is lower than the volatility of the price of a good relative to the price of the same good in a different country. Engel and Rogers (1996) find that the "border effect" introduces significant variation in the price of a good sold in different countries.
} 
directly in the consumer basket, or price stickiness at the consumer level.

We begin by adding international price discrimination by firms (below we refer to this specification as LCP), which may optimally choose to charge different prices, $\tilde{P}_{H, t}(f)$ at home and $\tilde{P}_{H, t}^{*}(f)$ abroad, to maximize the present discounted value of future profits. The presence of price rigidities implies that firms have to take into account the entire path of the future expected nominal exchange rate $S_{t}$ when setting foreign prices for their products; thus, the LOOP need not hold. In addition to the home bias mechanism described above, the real exchange rate now responds to international price differences of the same good. Linearizing the definition of the real exchange rate around the steady state yields

$$
q_{t}=\left[\mu^{*}+\mu-1\right] \tau_{t}+\mu \varepsilon_{t}^{H}+\mu^{*} \varepsilon_{t}^{F},
$$

where $\varepsilon_{t}^{H}$ and $\varepsilon_{t}^{F}$ measure deviations from the LOOP that arise due to local currency pricing coupled with nominal rigidities: $\varepsilon_{t}^{F} \equiv p_{F, t}^{*}+s_{t}-p_{F, t}$ and $\varepsilon_{t}^{H} \equiv p_{H, t}^{*}+s_{t}-p_{H, t}$.

The second method, à la Devereux and Engel (2007) and to which we refer as PCPRet, assumes that intermediate (wholesale) goods are priced in producer currency (PCP), but final goods available for consumption and composed of both imported and locally produced intermediates are priced in local currency by the retail sector. Combined with sticky prices, this setup corresponds to the recent finding that, in the short-run, exchange rate pass-through into import prices is quite high while consumer price index (CPI) inflation is insulated from exchange rate movements 8

Retailers purchase home and foreign intermediate goods at the (optimally set) prices $p_{H, t}$ and $p_{F, t}^{*}$ such that the retailers' marginal costs are given by

$$
m c f_{t}=\mu p_{H, t}+(1-\mu)\left[s_{t}+p_{F, t}\right]
$$

The retailers then optimally set their own prices $p_{R, t}$ at a markup above the marginal cost.

\footnotetext{
${ }^{8}$ See Campa and Goldberg (2005) and Mumtaz, Oomen and Wang (2006) for empirical evidence.
} 
Given this more detailed treatment of the firms' international price-setting choices, below we have to carefully differentiate between the potentially different durations of nominal contracts. To this end, we let $\alpha_{H, w}$ and $\alpha_{H, w}^{*}$ measure the degree of Calvo price stickiness faced by Home wholesale firms in the local and export markets (the corresponding foreign parameters are given by $\alpha_{F, w}^{*}$ and $\alpha_{F, w}$ ), and $\alpha_{H, r}\left(\alpha_{F, r}\right.$ abroad) measure the corresponding stickiness in the retail sector.

3. Nontraded goods. The second way of lowering the degree of pass-through from exchange rates to inflation is to introduce nontraded goods. To do so, we add a continuum of firms which, similar to the producers of the tradables above, hire capital and labor from local households to produce one of the varieties of nontradable goods, which are then bundled together analogously to the tradable output. The consumption aggregate in the household's utility function is now given by

$$
C_{t}=\left[\eta^{\frac{1}{\sigma_{N T}}}\left[C_{N, t}\right]^{\frac{\sigma_{N T}-1}{\sigma_{N T}}}+(1-\eta)^{\frac{1}{\sigma_{N T}}}\left[C_{T, t}\right]^{\frac{\sigma_{N T}-1}{\sigma_{N T}}}\right]^{\frac{\sigma_{N T}}{\sigma_{N T}-1}}
$$

Here $\sigma_{N T}$ denotes the elasticity of substitution between tradables and nontradables, and $0<\eta<1$ determines the relative weight of nontradables in consumption. Investment used to augment capital stock, as well as government purchases, are now also composed of traded and nontraded goods according to (5). The new CPI level is described by

$$
P_{t}=\left[\eta P_{N, t}^{1-\sigma_{N T}}+(1-\eta) P_{T, t}^{1-\sigma_{N T}}\right]^{\frac{1}{1-\sigma_{N T}}}
$$

The definitions of $C_{T, t}$ and $P_{T, t}$ are still given by equations (2) and (3a).

It is clear from (6) that, even in the absence of home bias, local currency pricing, or nominal rigidities (in which case the composition and the price of the tradable baskets equalize), relative technological growth between traded and nontraded sectors can, through the Balassa-Samuelson effect, lead to movements in the real exchange rate.

4. Incomplete markets. While the existence of the internationally traded bond simplifies aggregation 
by equalizing marginal utilities of wealth in the two countries, it has an uncomfortable implication that the variation in the relative consumption growth rates is directly linked to RER movements, contrary to what is seen in the data. This observation has motivated many researchers to examine the incomplete international financial markets specification, which has the potential to lower the theoretical correlation to the empirically observed levels.

We continue assuming (for model tractability) that all consumers can perfectly share risks within a country; additionally, a risk-free bond issued by the foreign country can be traded internationally. The bond is denominated in foreign currency and offers nominal interest rate $i_{t}^{*}$. We furthermore assume that when borrowing from abroad, home households must pay a risk premium, which depends on the home country's position in the international asset market and on the home and foreign international interest rate differential.

\subsection{Sources of inflation dynamics}

At this point, it perhaps useful to summarize the various mechanisms that contribute to the dynamics of inflation in our model. In a standard closed economy setting, the New Keynesian Phillips Curve (NKPC) takes the form

$$
\pi_{H, t}=\phi_{1} \widehat{r m c}_{t}+\phi_{2} E_{t} \pi_{H, t+1}
$$

where $\pi_{H, t}$ measures the change in the home country consumer price level, $\widehat{r m c}_{t}$ captures the deviation from the steady state of the real marginal cost, and the parameters $\phi_{1}$ and $\phi_{2}$ depend on the degree of price stickiness $\alpha$ and on the household time discount factor $\beta 9^{9}$ The real marginal cost is a function of the real interest rate $r_{t}$, the real wage $w_{t}$ and the state of technology $z_{T, t}$ :

$$
\widehat{r m c_{t}}=\nu \widehat{r}_{t}+(1-\nu) \widehat{w_{t}}-(1-\nu) \widehat{z_{T, t}}
$$

\footnotetext{
${ }^{9}$ This model has one pricing sector (wholesale) which sets prices in producer currency; hence, we only need one measure of price stickiness $\alpha$. More specifically, in this framework we have $\phi_{1}=\alpha^{-1}(1-\alpha)(1-\alpha \beta)$ and $\phi_{2}=\beta$.
} 
Examining the expressions above, we see that the inherent persistence in inflation can come from three sources: (a) the underlying persistence in technology $z_{T, t}$, which influences the evolution of marginal costs; (b) monetary policy sluggishness $\rho_{i}$, which affects the dynamics of real interest rates and therefore of marginal costs as well; and (c) the degree of nominal rigidities $\alpha$. Hence, in response to Fuhrer and Moore (1995), the efforts to "hardwire" a certain degree of inflation persistence in the closed-economy literature have centered on adjusting the parameters of the technology process; introducing habit formation into the consumer utility function (which indirectly affects the path of marginal costs by introducing demand persistence); adding backward-looking indexation for those firms that do not reset their prices in any given period (and thereby increasing inflation sluggishness above the level dictated by the parameter $\alpha$ ); and increasing the degree of interest rate inertia in the central bank reaction function.

In an open economy setting, the NKPC is altered in one of several different ways, depending on the exact specification of international pricing contracts. We examine several of them in turn.

In the most basic setting (which will call HBias in the simulations below), firms in each country set only one price for their products (producer currency pricing), so that import prices depend on the movements in the nominal exchange rate. The evolution of (for example) the home country's CPI is now governed by

$$
\pi_{t}=\mu \phi_{1} \widehat{r m c}_{t}+(1-\mu) \phi_{1}^{*} \widehat{r m c}_{t}^{*}+(1-\mu) \Delta s_{t}+\mu \phi_{2} E_{t} \pi_{H, t+1}+(1-\mu) \phi_{2}^{*} E_{t} \pi_{F, t+1}^{*}
$$

where $\pi_{H, t}$ and $\pi_{F, t}^{*}$ capture producer price inflations, $\Delta s_{t}$ measures nominal exchange rate depreciation, and $\mu$ indicates the level of home bias in consumption; $\phi_{1}$ and $\phi_{2}$ (and their foreign counterparts) are defined as above. In addition to the direct influence of the nominal exchange rate of the foreign marginal costs, the home CPI inflation also depends on the cross-country correlations between the two technology and the two interest rate shock processes. We should note that, ultimately, persistence and volatility of the nominal (and real) exchange rate stem from the same fundamental rigidities (technology, monetary 
policy inertia, and price stickiness) as does inflation dynamics in the closed economy setting. Nonetheless, the various open economy extensions allow us to recombine these fundamental closed-economy frictions in more complex ways to arrive at different values of CPI volatility and persistence.

The addition of local currency pricing (LCP, such that each firm sets two prices - one in each currency — for the same good) adds another layer of dynamics to the inflation process:

$$
\pi_{t}=\underbrace{\mu_{t} \phi_{1} \widehat{r m c}_{t}+\left(1-\mu_{t}\right) \phi_{1}^{*} \widehat{r m c_{t}^{*}}}_{\text {Marginal cost/technology effects }}+\underbrace{\left(1-\mu_{t}\right) \phi_{1}^{*}\left[p_{F, t}^{*}+s_{t}-p_{F, t}\right]}_{\text {Deviation from LOOP }}+\underbrace{\mu_{t} \phi_{2} E_{t} \pi_{H, t+1}+\left(1-\mu_{t}\right) \phi_{2}^{*} E_{t} \pi_{F, t+1}}_{\text {Forward-looking behavior }}
$$

The key difference between (9) and (8) comes from the firm decision-making process: in the former, they aggregate the current and expected future demand conditions in both economies when choosing a price, whereas in the latter they respond to changes in the home and foreign economy separately. Thus, generally, the deviations from the LOOP can be driven by differences in consumer preferences, varying degrees of monopolistic power at home and abroad, and unexpected movements in the nominal exchange rate.

If we go back to the basic open economy setup (producer currency pricing) and add to it price rigidity at the retail level (PCPRet), the Phillips curve, analogous to the closed economy case (7), is given by

$$
\pi_{t}=\psi_{1} r \widehat{m c}_{r, t}+\psi_{2} E_{t} \pi_{t+1}
$$

where $r \widehat{m c}_{r, t}$ captures the real marginal cost of retailers normalized in CPI, and the (nominal) marginal cost itself has the dynamics analogous to (8):

$$
\Delta m c_{r, t}=\mu \phi_{1} \widehat{r m c}_{t}+(1-\mu) \phi_{1}^{*} \widehat{r m c}_{t}^{*}+(1-\mu) \Delta s_{t}+\mu \phi_{2} E_{t} \pi_{H, t+1}+(1-\mu) \phi_{2}^{*} E_{t} \pi_{F, t+1}^{*}
$$

In this setup, we have to differentiate between the wholesale price stickiness parameters $\alpha_{H, w}=\alpha_{H, w}^{*}$ and $\alpha_{F, w}=\alpha_{F, w}^{*}\left(\right.$ contained in $\phi_{1}$ and $\left.\phi_{1}^{*}\right)$ and the corresponding retail parameters $\alpha_{H, r}$ and $\alpha_{F, r}$ in $\psi_{1}$ and $\psi_{1}^{* 10}$

\footnotetext{
${ }^{10}$ We now have $\psi_{1}=\alpha_{H, r}^{-1}\left(1-\alpha_{H, r}\right)\left(1-\alpha_{H, r} \beta\right)$ and $\psi_{2}=\beta$.
} 
Modeling the second production sector (of nontraded goods) adds another weighted marginal cost process to (7) or (8). However, in the open economy setting, nontraded goods influence domestic CPI through an additional channel, the well-known Balassa-Samuelson effect: a technological improvement in the tradable sector leads to higher economy-wide wages. Assuming an unchanged level of productivity in the nontraded sector, higher labor costs drive up the price of nontradables, increasing the aggregate price level at home and thus causing exchange rate appreciation. Theoretically, in models with a nontraded sector, the real exchange rate can be written as a function of the relative movements in sectoral productivities across countries:

$$
q_{t}=f\left[\left(z_{T, t}-z_{N, t}\right)-\left(z_{T, t}^{*}-z_{N, t}^{*}\right)\right]
$$

Countries that enjoy faster technological progress (which more often than not is concentrated in the tradables sector) consequently experience real exchange rate appreciation since rising costs of production factors (labor and capital) drive up prices in the nontradable sector. In the presence of price rigidities, real and nominal exchange rates move closely together; the latter in turn enters the NKPC though one of the equations (8)- 10$)$.

Finally, the incomplete markets setup can affect inflation dynamics through the interest rate channel. To see this, we combine the log-linearized versions of the home household's first order conditions with respect to its asset holdings to obtain a modified version of the UIP condition:

$$
i_{t}-i_{t}^{*}=E_{t} \Delta s_{t+1}+\varphi_{t}
$$

where the variable $\varphi_{t}$ depends on the home country's foreign debt to GDP ratio. Now the dynamics of the nominal exchange rate, which in turn enters all the open-economy Phillips curve versions considered in our paper, are influenced by the behavior of the risk premium in addition to the usual interest rate differential $i_{t}-i_{t}^{*}$. Depending on how one models international borrowing (whether it is undertaken privately, by the government, or a combination of the two), consumer portfolio decisions and fiscal policy may influence 
inflation dynamics through their effects on the borrowing risk premium.

We next turn to quantifying the differences in inflation volatility and persistence across the open-economy specifications described above.

\section{Moments of simulated inflation}

Our analysis of the effects of the various open economy features on the resulting moments of inflation proceeds in two stages. First, we calibrate the two countries in our model to be completely symmetric (thereby abstracting from the reported empirical differences between developed and developing economies) and then add or vary, one at a time, the open economy extensions described in the previous section. The initial goal is to identify those parameters which can, at least in principle, affect the volatility and persistence of the simulated inflation series. Once we have identified a subset of such promising parameters, in the second stage of our analysis (Section 5) we allow them to differ when calibrating our model more carefully to a pair of developed-developing economies. The goal of this second exercise is to compare the resulting differences in the magnitudes of the simulated inflation moments to the empirical differences reported in Section 2

\subsection{Calibration and business cycle properties}

Each time period in the model corresponds to one quarter. The parameterization of the model follows Ahmad, Lo, and Mykhaylova (2013a), except as discussed below. Most of parameter values are quite common and noncontroversial in the international DSGE literature. We calibrate three parameters to bring the moments of the model in close correspondence with the U.S.-UK data; correspondingly, we set $M=1$ and $M^{*}=6$.

We calibrate the variance-covariance matrix of the two monetary shock processes $\left\{\varepsilon_{i, t}, \varepsilon_{i, t}^{*}\right\}$ to match the 
empirical volatility and cross-correlation of the two GDPs, and the value of the capital adjustment costs to match the relative consumption-GDP volatility observed in the U.S. data. We keep the monetary shock matrix and the adjustment cost parameter constant across all one-sector specifications of the model, and adjust the values slightly when we switch to the two-sector specifications. This way, we can interpret the differences in the inflation outcomes as stemming from the structural changes in the model rather than from changes in parameter values.

The only other parameter that varies across model specifications is the degree of home bias in consumption, $\mu$. To model a closed economy, we set $\mu=1$; we also set $\mu=0.6$ and 0.75 to test the effects of greater openness on inflation persistence.

Solution to the model is found using perturbation methods described in Schmitt-Grohé and Uribe (2004) and Collard and Juillard (2001); computer code is written in Dynare (Collard and Juillard, 2009).

Table 6 in Appendix A presents the business cycle properties of the simulated HP-filtered data. In addition to examining the four extensions outlined above, we also study a combination of all of them. Thus, rows 16 and 24 of Table 6 refer to the specification that includes home bias in consumption, the first version of local currency pricing (LCP), nontraded goods, and incomplete financial markets.

\subsection{Simulation results}

Given our choice of the parameters, we consider 14 different versions of the model: two closed economy versions (with one and two production sectors), six open economy versions with $\mu=0.6$ (only home bias, two local currency pricing specifications, incomplete markets, non-traded goods, and the combination of all four extensions), and the same six versions with $\mu=0.75$. We simulate each of the 14 versions 1000 times, with each simulation covering 5000 periods (quarters). We initially set the two countries to be symmetric in size: $M=M^{*}=1$. However, we also repeat all the simulations after allowing for differences 
in country size, where we calibrate the model to the relative size of the U.S.-UK economies. The results of the simulations are presented in Tables 2 and 3 .

\begin{tabular}{|c|c|c|c|c|c|}
\hline \multicolumn{2}{|c|}{ Persistenc } & Volatility & & Persistence & Volatility \\
\hline \multicolumn{3}{|l|}{ Data } & \multicolumn{3}{|c|}{ Closed economy models } \\
\hline Full sample & 0.600 & 0.026 & One-sector & 0.478 & 0.025 \\
\hline Developing & 0.511 & 0.032 & Two-sector & 0.515 & 0.023 \\
\hline Developed & 0.866 & 0.012 & & & \\
\hline \multicolumn{3}{|c|}{ Open economy models, $\mu=0.75$} & \multicolumn{3}{|c|}{ Open economy models, $\mu=0.60$} \\
\hline Home bias & 0.471 & 0.026 & Home bias & 0.448 & 0.027 \\
\hline LCP & 0.496 & 0.025 & LCP & 0.497 & 0.024 \\
\hline PCPRet & 0.663 & 0.017 & PCPRet & 0.663 & 0.017 \\
\hline Incomplete & 0.457 & 0.026 & Incomplete & 0.374 & 0.029 \\
\hline NT goods & 0.491 & 0.025 & NT goods & 0.460 & 0.026 \\
\hline NT+LCP+Incom. & 0.531 & 0.023 & $\mathrm{NT}+\mathrm{LCP}+$ Incom. & 0.532 & 0.023 \\
\hline
\end{tabular}

Table 2: Simulated inflation volatility and persistence for the equal country size case.

Note: Data refers to the median values of volatility and persistence.

Starting with the benchmark case of equal country size, we see that volatility in the closed economy versions of the model is close to the empirical full sample average. The closed economy model with two sectors has slightly higher inflation persistence, although in both cases it is less than the full sample average of 0.6. When we look at the results for the open economy versions of the model, we see that volatility is once again approximately equal to what is seen in the average across all countries, although higher than that observed in developed countries. Persistence is less than the full sample average, and even here none of the specifications truly approach the average level seen in developed countries. The version of the model that comes closest to matching the empirical inflation persistence is PCPRet, which incorporates additional price inertia via the retail sector. In particular, this variant of the model is able to match the volatility in the data for developed countries fairly well, as well as having the greatest degree of persistence among all the studied specifications.

Since our model allows us to decouple country size from structural features, like the openness of a country 
(which itself is captured through home bias), we use it to explore whether country size impacts the level of persistence and volatility; the results are reported in Table 3 . Once again, the volatility generated by the model approaches the levels seen in the data, although persistence is still too low. The PCPRet version of the model is again the closest to the data in terms of both metrics. The results suggest that the versions of the model considered in this study are unable to match the extent of inflation persistence observed in developed countries, although they come close to matching the persistence in developing countries. With regards to volatilities, we find the opposite: the volatility of inflation generated by the models exceeds the volatility observed in developed countries, although it falls short of the developing countries' estimates.

\begin{tabular}{|c|c|c|c|c|}
\hline & Persistence & Volatility & & \\
\hline \multicolumn{5}{|l|}{ Data } \\
\hline Full sample & 0.600 & 0.026 & & \\
\hline Developing & 0.511 & 0.032 & & \\
\hline \multirow[t]{3}{*}{ Developed } & 0.866 & 0.012 & & \\
\hline & \multicolumn{2}{|c|}{ Large Country } & \multicolumn{2}{|c|}{ Small Country } \\
\hline & Persistence & Volatility & Persistence & Volatility \\
\hline \multicolumn{5}{|l|}{ Closed economy } \\
\hline One-sector & 0.478 & 0.025 & 0.474 & 0.026 \\
\hline Two-sector & 0.516 & 0.023 & 0.516 & 0.023 \\
\hline \multicolumn{5}{|c|}{ Open economy, $\mu=0.75$} \\
\hline Home bias & 0.462 & 0.027 & 0.476 & 0.026 \\
\hline $\mathrm{LCP}$ & 0.497 & 0.025 & 0.488 & 0.025 \\
\hline PCPRet & 0.663 & 0.017 & 0.664 & 0.017 \\
\hline Incomplete & 0.464 & 0.026 & 0.481 & 0.025 \\
\hline NT goods & 0.489 & 0.025 & 0.520 & 0.023 \\
\hline NT+LCP+Incom. & 0.530 & 0.023 & 0.529 & 0.023 \\
\hline \multicolumn{5}{|c|}{ Open economy, $\mu=0.6$} \\
\hline Home bias & 0.463 & 0.027 & 0.477 & 0.026 \\
\hline $\mathrm{LCP}$ & 0.496 & 0.025 & 0.489 & 0.025 \\
\hline PCPRet & 0.664 & 0.017 & 0.664 & 0.017 \\
\hline Incomplete & 0.429 & 0.027 & 0.478 & 0.025 \\
\hline NT goods & 0.464 & 0.026 & 0.518 & 0.023 \\
\hline NT+LCP+Incom. & 0.532 & 0.023 & 0.529 & 0.023 \\
\hline
\end{tabular}

Table 3: Simulated inflation volatility and persistence when the two country sizes are unequal. Notes: (a) Data refers to the median values of volatility and persistence.

(b) Large economy $M^{*}=6$, small economy $M=1$. 
We note, however, that the results above come from a calibration of the model based on the business cycle properties of developed countries (more specifically, the U.S.-UK pair), and which abstracts from other features that researchers have included to match persistence in the data, such as backwards looking indexation, rule of thumb behavior, or habit formation. Yet, despite this, the structural features we explore are able to generate a reasonable amount of persistence. In the case of PCPRet, the structure of international pricing behavior can generate up to $75 \%$ of the persistence observed in the data. This in itself is very encouraging. It provides a potential route by which to generate the kinds of empirical regularities that we observed in the earlier section of the paper, purely from structural features within an economy.

Section 3.3 described the effects of the various open economy features studied in our paper on the NKPC. We pursue the analysis further by quantifying the strength of the exchange rate pass-through (ERPT) to consumer prices in the different model specifications reported in Table 2 by construction, ERPT to import prices is either one (HBias, PCPRet, Incomplete, and NTGoods) or zero (LCP, NT+LCP+Incom) 11 For easier comparison with the existing literature, we follow the methodology in Campa and Goldberg (2005) and Gopinath et al. (2010) and estimate the following regression using our simulated data:

$$
\pi_{t}=\alpha_{i}+\sum_{j=0}^{n} \beta_{j} \Delta s_{t-j}+\sum_{j=0}^{n} \gamma_{j} \pi_{t-j}^{*}+\sum_{j=0}^{n} \delta_{i, j} \Delta y_{t-j}+\varepsilon_{i, t}
$$

For each model specification, we calculate the (cumulative) ERPT as the sum of coefficients on the exchange rate, $\sum_{j=0}^{n} \beta_{i, j}$, for $j \in\{0, \ldots, 20\}$; figure 3 presents the results of these calculations.

Most of the results of the ERPT estimations are quite unsurprising; in accordance with theory, the degree of pass-through increases with trade openness (lower value of $\mu$ ), and builds up over time. The presence of local currency pricing (be it direct, as in the LCP specification, or layered as in PCPRet) and nontraded goods insulate consumer prices from exchange rate fluctuations and thus lower ERPT relative to the

\footnotetext{
${ }^{11}$ Many papers have documented the relationship between the ERPT and the resulting degree of inflation persistence; see, for example, Flamini (2007), Granato, Lo, and Wong (2006), and Smets and Wouters (2002).
} 

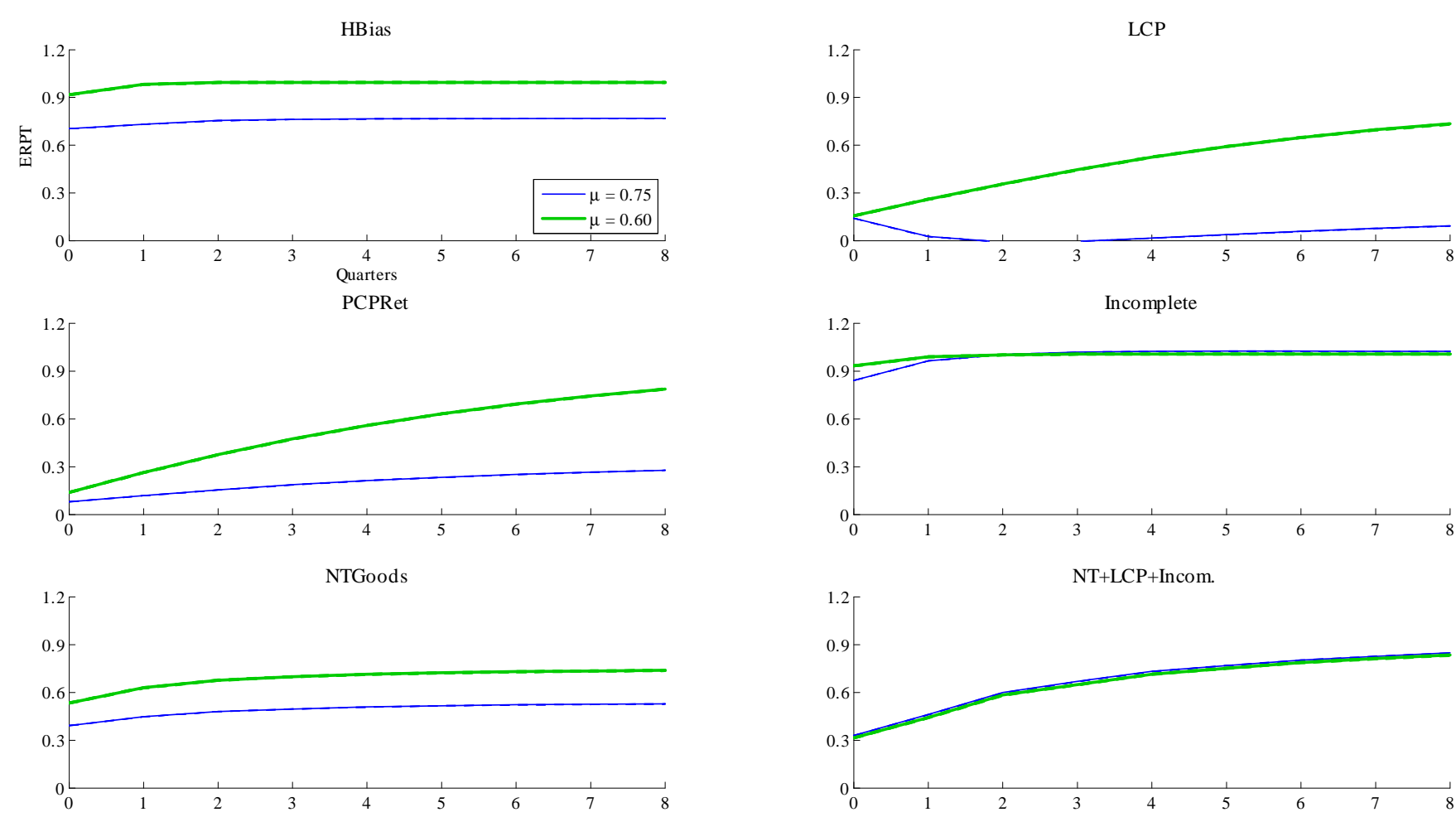

Figure 3: Aggregate exchange rate pass-through at different horizons in the baseline models.

baseline model. Interestingly, we find that incomplete financial markets dominate the dynamics of ERPT; comparing HBias and Incomplete specifications, we see that the UIP linkages outweigh the effects of trade openness on the degree of pass-through.

Overall, our findings above suggest that pricing in an international context may be an important aspect to consider when attempting to match inflation persistence and volatility in the data. Based on our results, we can form the following hypothesis: the structure of international pricing - which coincides closely with the degree of the exchange rate pass-through — has a significant impact on the moments of inflation and can in fact explain some of the empirically observed differences between developing and developed countries. In the next section, we explore this channel further and with different calibrations, including a developeddeveloping country pair. 

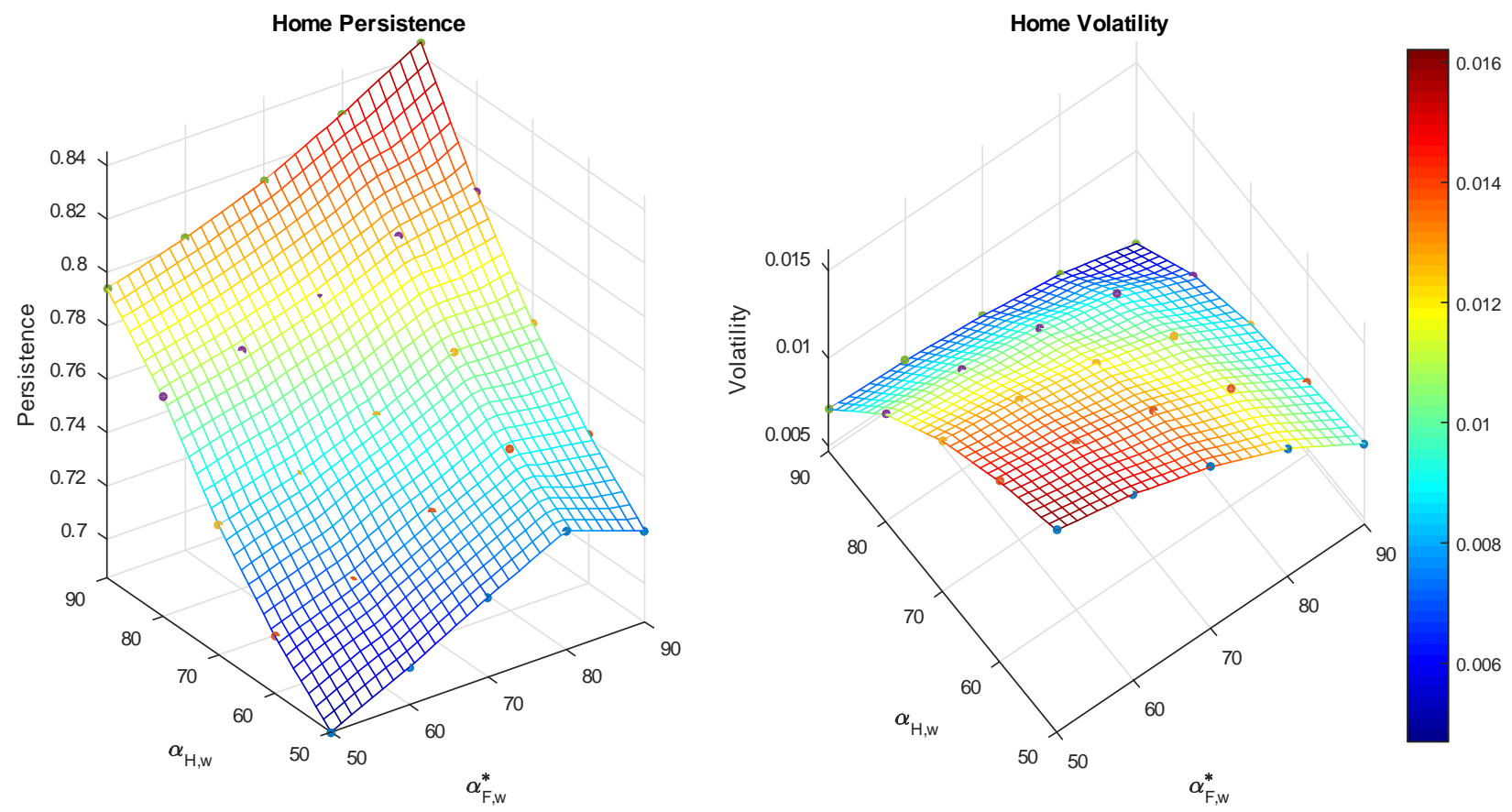

Figure 4: Moments of Home CPI inflation for different levels of domestic and foreign wholesale sector price stickiness in the PCPRet specification of the model.

\section{Impact of pricing contracts on inflation dynamics}

\subsection{The importance of nominal rigidities}

Holding all other country characteristics constant, differences in economic openness (measured as the degree of home bias in consumption) produce only a marginal change in the behavior of inflation (as demonstrated in Tables 2 and 30. However, equations (8)-10 suggest that the degree of ERPT should be directly affected by the frequency of price adjustments both on the wholesale and retail level. To understand the quantitative importance of nominal rigidities, we calculate inflation volatility and persistence in one of the studied setups - more specifically, PCPRet — for different values of retail and wholesale contract duration.

The results, presented in Figure 4, indicate that inflation persistence (volatility) is monotonically increasing (decreasing) in the duration of nominal rigidities in both countries in both wholesale and retail levels. 
In fact, for certain parameterizations we are able to replicate the empirical moments of inflation almost exactly. This finding suggests that, combined with the interaction between the wholesale and retail firms, an empirically plausible degree of nominal rigidities in each sector (for example, $\alpha_{H, w}=0.7$ and $\alpha_{H, r}=0.75$, corresponding to pricing contracts of about one year) can help to replicate the observed persistence of inflation.

To extend this line of inquiry further, we next turn to the impact on inflation moments of open economy features. The largest increase in inflation persistence (vis-à-vis the closed economy model) in Table 2 comes from the PCPRet setup. The main difference between the two specifications - aside from the existence of international trade - lies in the price-setting specification. Firms in the benchmark closed economy model sell their products directly to consumers, whereas the PCPRet economy features an additional layer of retailers that adds another layer of price stickiness to the CPI dynamics. We therefore augment the closed economy benchmark model with the retail level, and analyze the differences in the behavior of inflation between it and the PCPRet version.

Somewhat unexpectedly, the results of the simulations, presented in Table (4), indicate that the effect of nominal rigidities on the inflation moments dominates that of trade openness: for a given set of parameter values, inflation volatility and persistence are quite similar in open and closed economies. This finding allows us to revisit the original claim in Fuhrer and Moore (1995) that nominal rigidities in and of themselves are unable to bring the modeled moments of inflation in line with empirical evidence. In fact, it is entirely possible to reconcile the simulated and observed inflation dynamics simply by adding a retail sector to the standard closed economy DSGE framework, eliminating the need for other frictions (backward-looking indexation or habit formation in consumption) now used in the literature to resolve the discrepancy. 


\begin{tabular}{|c|c|c|c|c|}
\hline \multicolumn{5}{|c|}{ Panel A } \\
\hline & \multirow{2}{*}{\multicolumn{2}{|c|}{$\begin{array}{c}\text { Closed } \\
\left(\alpha_{H, r}=0.75\right)\end{array}$}} & \multicolumn{2}{|r|}{ Open } \\
\hline & & & \multicolumn{2}{|c|}{$\left(\alpha_{H, r}=0.75 ; \alpha_{F, r}=0.75 ; \alpha_{F, w}^{*}=0.5\right)$} \\
\hline$\alpha_{H, w}$ & Volatility & Persistence & Volatility & Persistence \\
\hline 0.5 & 0.016 & 0.681 & 0.016 & 0.686 \\
\hline 0.6 & 0.014 & 0.716 & 0.015 & 0.707 \\
\hline 0.7 & 0.012 & 0.753 & 0.013 & 0.734 \\
\hline 0.8 & 0.009 & 0.796 & 0.011 & 0.768 \\
\hline 0.9 & 0.005 & 0.847 & 0.007 & 0.794 \\
\hline \multicolumn{5}{|c|}{ Panel B } \\
\hline & \multicolumn{2}{|c|}{ Closed } & \multicolumn{2}{|r|}{ Open } \\
\hline & \multicolumn{2}{|c|}{$\left(\alpha_{H, w}=0.5\right)$} & \multicolumn{2}{|c|}{$\left(\alpha_{H, w}=0.5 ; \alpha_{F, w}^{*}=0.5 ; \alpha_{F, r}=0.75\right)$} \\
\hline$\alpha_{H, r}$ & Volatility & Persistence & Volatility & Persistence \\
\hline 0.55 & 0.029 & 0.554 & 0.030 & 0.575 \\
\hline 0.65 & 0.023 & 0.617 & 0.023 & 0.629 \\
\hline 0.75 & 0.016 & 0.681 & 0.016 & 0.686 \\
\hline 0.85 & 0.010 & 0.749 & 0.009 & 0.745 \\
\hline 0.95 & 0.003 & 0.822 & 0.002 & 0.807 \\
\hline
\end{tabular}

Table 4: Simulated inflation volatility and persistence for a closed economy with a retail sector vs. open economy PCPRet version.

Notes: (a) Data refer to the median values of volatility and persistence.

(b) Panel A varies $\alpha_{H}, w$ while holding $\alpha_{H}, r$ constant in the closed economy version, and holding $\alpha_{H}, r$, $\alpha_{F}, r$, and $\alpha_{F}^{*}, w$ constant in the open economy version.

(c) Panel $\mathrm{B}$ varies $\alpha_{H}, r$ while holding $\alpha_{H}, w$ constant in the closed economy version, and $\alpha_{H}, w, \alpha_{F}^{*}, w$, and $\alpha_{F}, r$ constant in the open economy version.

\subsection{International asymmetries in inflation dynamics}

Given our results so far, we next want to take a closer look at the relative degree of nominal rigidities in the wholesale and retail sectors in the developed versus developing economies with the goal of explaining the empirical regularities detailed in Table 1. When examining the differences between developing and developed economies, we must analyze the entire monetary policy/price-setting choices/ERPT nexus. Several authors have documented the decline in ERPT during the last two decades in many countries. The causes of this decline can be attributed to macroeconomic factors - more specifically, to the switch toward inflation targeting by many economies, as argued in Taylor (2000) and Devereux and Yetman (2010) — and/or to changes in the microeconomic pricing decisions of firms, related perhaps to the composition of import 
bundles, discussed in Campa and Goldberg (2005). In all likelihood, firms' pricing strategies and monetary policy regimes influence one another over time. However, insofar as it is informative to understand the marginal contributions of each of these two mechanisms to inflation dynamics, below we continue to abstract from changes in the central bank reaction function to keep our focus squarely on the exchange rate-inflation nexus.

Firms' pricing decisions are a function of the industrial organization and overall stability of the economy, reflected (among others) in the degree of import-export substitutability, firms' market power, and the magnitude of exchange rate shocks. The explicit modeling of these decisions is outside the scope of this paper; we instead focus on two outcomes of such decisions: the frequency of price adjustments and the choice of invoice currency (local versus producer currency pricing).

The magnitude of nominal rigidities in the developed countries has been well-documented in the literature: it is usually assumed that U.S. firms change their prices on average once a year (Canzoneri et al., 2008), with European firms reoptimizing prices even less frequently (Adolfson et al., 2007). Information on the extent of nominal rigidities in developing countries is more sparse; nonetheless, the existing country studies point in the same direction: firms tend to reset their prices more frequently - about once per quarterthan in the developed economies ${ }^{12}$ Moreover, several studies have shown that exporters set prices in their own currency when their product destination markets are characterized by high inflation levels and exchange rate volatility; conversely, they set prices in consumer currency in low-inflation and exchange rate volatility environments (Campa and Goldberg, 2005; Devereux and Engel, 2001; Devereux et al., 2004). Consequently, the degree of ERPT is positively related to the level of inflation and to the volatility of the exchange rate. Fuentes (2007) presents evidence that EPRT to import prices is higher in developing countries than in advanced economies.

\footnotetext{
${ }^{12}$ More specifically, firms reset their prices on average once every 3-6 months in Pakistan (Choudhary et al., 2011); 2.6 months in Sierra Leone (Kovanen, 2006); 2.7-3.8 months in Brazil (Gouvea, 2007); and 3 months in Chile (Medina et al., 2007).
} 
The literature on the choice of currency invoicing has identified the U.S. dollar and, to a lesser but growing extent, the euro as the vehicle currencies in international trade. Bacchetta and van Wincoop (2005), Goldberg and Tille (2006), and ECB (2014) report that a significant portion of U.S. and European imports are priced in consumer currency, shielding the two regions' CPI inflations from exchange rate movements. More specifically, over 50 percent of goods imported to (exported from) the Eurozone economies from (to) non-Eurozone economies are invoiced in Euros, and over 90 percent of U.S. imports and exports are invoiced in dollars.

Based on all of the above observations, we will assume that Home (developed economy) imports are priced in Home currency, with prices reoptimized relatively infrequently; more specifically, we set $\alpha_{H, w}=\alpha_{F, w}=0.50$ and $\alpha_{H, r}=0.75$. Asymmetrically, imports into the Foreign economy are also priced in Home currency with infrequent adjustment episodes, whereas local prices of intermediates are much less sticky: $\alpha_{H, w}^{*}=0.5$ and $\alpha_{F, w}^{*}=0 ;$ we also set $\alpha_{F, r}=0.25$. In the simulations below, we study the impact of these asymmetries on our results one at a time

I. We first assume that both countries' imports are priced in producer currency but with different degree of nominal rigidities ("Both PCPRet, asymmetric $\alpha$ 's"): $\alpha_{H, w}=0.5, \alpha_{F, w}^{*}=0, \alpha_{H, r}=0.75$, and $\alpha_{F, r}=0.25$.

II. Home firms choose only one price in their own currency regardless of the product destination, whereas foreign firms price to market (they export their goods to the Home economy in the Home currency, but sell their product locally in the Foreign currency), the duration of all pricing contracts is symmetric and set at the developed country level: $\alpha_{H, w}=\alpha_{F, w}^{*}=\alpha_{F, w}=0.5, \alpha_{H, r}=\alpha_{F, r}=0.75$.

III. Home firms choose only one price in their own currency regardless of the product destination, whereas foreign firms price to market (they export their goods to the Home economy in the Home currency, but 
sell their product locally in the Foreign currency), the duration of all pricing contracts is asymmetric:

$\alpha_{H, w}=\alpha_{F, w}=0.5, \alpha_{F, w}^{*}=0, \alpha_{H, r}=0.75$, and $\alpha_{F, r}=0.25$

\begin{tabular}{|l|c|c|c|c|}
\hline \multirow{2}{*}{} & \multicolumn{2}{|c|}{ Home Country } & \multicolumn{2}{c|}{ Foreign Country } \\
\cline { 2 - 5 } & Persistence & Volatility & Persistence & Volatility \\
\hline \hline$\mu=0.75$ & 0.648 & 0.017 & 0.184 & 0.137 \\
I: Both PCPRet, asymmetric $\alpha$ 's & 0.676 & 0.016 & 0.676 & 0.016 \\
II: LCPRet/PCPRet, symmetric $\alpha$ 's & 0.673 & 0.015 & 0.157 & 0.163 \\
III: LCPRet/PCPRet, asymmetric $\alpha$ 's & & & & \\
\hline & & & & \\
$\mu=0.60$ & & 0.017 & 0.210 & 0.124 \\
I: Both PCPRet, asymmetric $\alpha$ 's & 0.644 & 0.016 & 0.676 & 0.016 \\
II: LCPRet/PCPRet, symmetric $\alpha$ 's & 0.676 & 0.015 & 0.182 & 0.144 \\
III: LCPRet/PCPRet, asymmetric $\alpha$ 's & 0.678 & & & \\
\hline
\end{tabular}

Table 5: Simulated inflation volatility and persistence for different international pricing strategies and invoicing currencies.

We find that the currency of pricing contracts does not make much difference for the resulting consumer price dynamics (compare setups I and III in Table 5). However, allowing for different duration of pricing contracts by the exporting firms allows us to reproduce the asymmetric moments of inflation reported in the first part of the paper. Echoing the results of the previous section, we also conclude that the degree of trade openness in and of itself has almost no impact on the volatility and persistence of inflation. These findings are also mirrored in the behavior of ERPT. The difference in the Home and Foreign ERPT magnitude comes primarily from the degree of nominal rigidities, although we can see (by examining the top left and the top right panels of Figure 5 that consumer pricing on the wholesale level provides an additional layer of insulation from exchange rate movements for the Home economy.

\section{Conclusions and future work}

The question concerning the degree of inflation persistence is far from settled in both empirical and theoretical literature. While time series studies present conflicting evidence as to the observed sluggishness of inflation in different countries and across different regimes, theoretical models have been frequently 

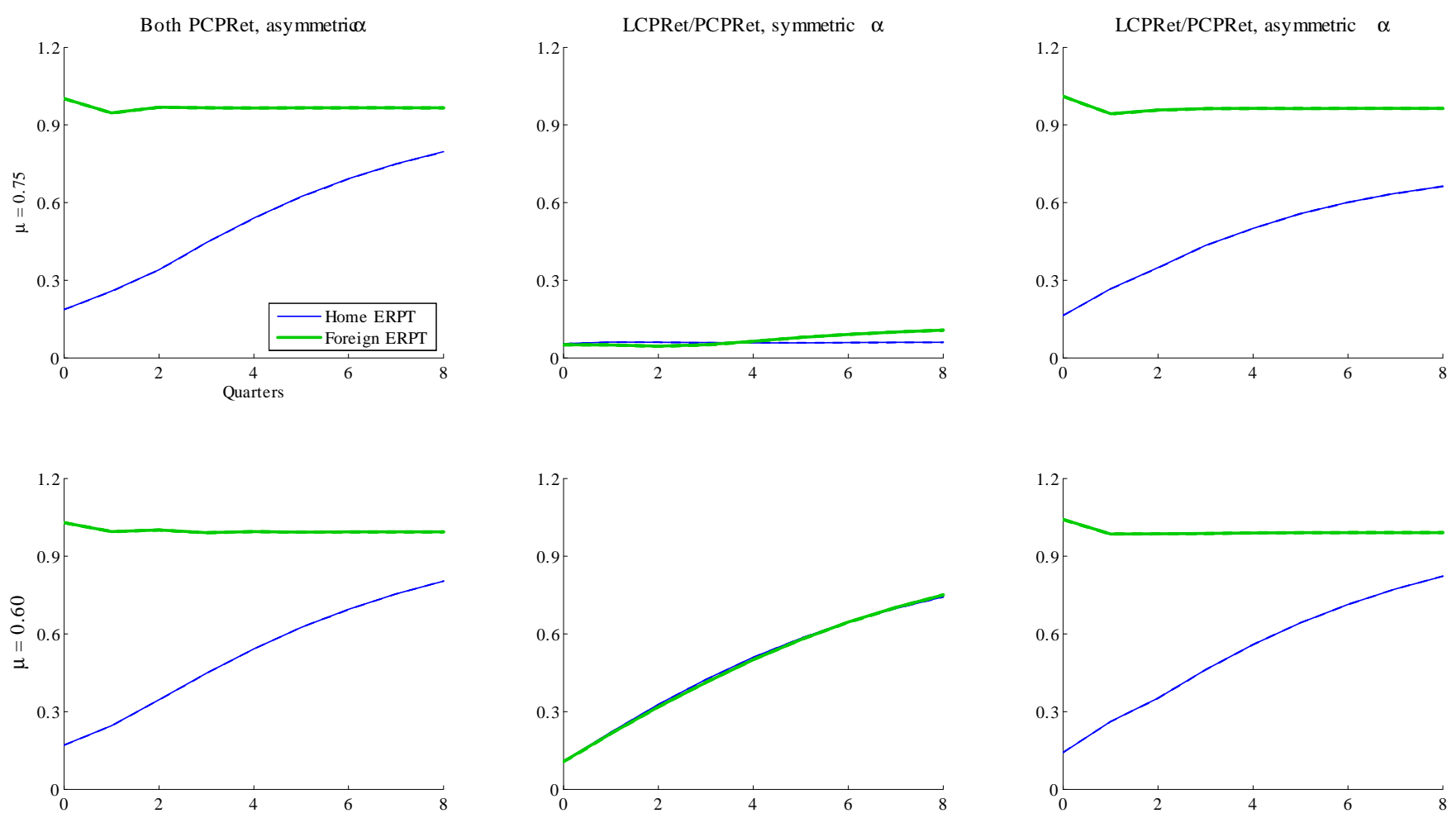

Figure 5: Aggregate exchange rate pass-through at different horizons in the models with asymmetric Home/Foreign pricing structure. 
equipped with backward-looking price indexation and habit formation in consumption to increase the resulting inflation persistence. We contribute to the debate by considering several open-economy extensions of the widely-used New Keynesian Phillips Curve that might explain inflation patterns observed in the data.

Based on a dataset covering 161 countries during the 1970-2013 period, we find that developing (developed) countries tend to have higher (lower) inflation volatility and lower (higher) inflation persistence. Comparing the moments of simulation inflation from a number of open economy frameworks, which differ in the degree of home bias, exchange rate pass-though, and financial market completeness, we find that the structure of international price setting is the most promising feature that can explain the empirical regularities in the data. More specifically, the lower degree of pass-through from exchange rates to national prices can explain the higher persistence and lower volatility of inflation in developed countries; the opposite is true for the developing economies.

We should note that although volatility of the simulated inflation come close to the median volatility in the data, none of the open economy features we consider - either in isolation or jointly - can replicate the high inflation persistence we see in the developed countries' time series. Yet, despite this, we find that our version of the model that incorporates a retail sector is able to generate approximately $75 \%$ of the persistence observed in the raw data by itself, and without other features that researchers have utilized to induce persistence, like rule of thumb behavior, or backwards looking indexation.

Our findings outline several promising avenues for future research. First, we have kept the parameters of the monetary policy rules constant across countries and across model specifications; however, given the link between exchange rate dynamics and the resulting inflation persistence, it is important to consider the impact of exchange rate targeting, above and beyond inflation smoothing, on the resulting behavior of prices. On a related note, if the structure of the cross-border pricing contracts-local versus producer 
currency prices and/or the degree of nominal rigidities - is an optimal response by firms to the structural differences between countries, the optimal monetary policy response may need to be revisited.

\section{References}

[1] Adolfson, M., Laséen, S., Lindé, J., Villani, M., 2007. Bayesian estimation of an open economy DSGE model with incomplete pass-through. Journal of International Economics, 72, 481-511.

[2] Aguiar, M., Gopinath, G., 2007. Emerging market business cycles: the cycle is the trend. Journal of Political Economy, 115, 69-102.

[3] Ahmad, Y., Lo, M.C., Mykhaylova, O., 2013a. Causes of nonlinearities in low-order models of the real exchange rate. Journal of International Economics, 91, 128-141.

[4] Ahmad, Y., Lo, M.C., Mykhaylova, O., 2013b. Volatility and persistence of simulated DSGE real exchange rates. Economics Letters, 119, 38-41.

[5] Aksoy, Y., Orphanides, A., Small, D., Weiland, V., Wilcox, D., 2006. A quantitative exploration of the opportunistic approach to disinflation. Journal of Monetary Economics, 53, 1877-93.

[6] Andrews, D., 1993. Tests for parameter instability and structural change with unknown change point. Econometrica, 61, 821-56.

[7] Andrews, D., Chen, H.-Y., 1994. Approximately median-unbiased estimation of autoregressive models. Journal of Business \& Economic Statistics, 12, 187-204.

[8] Bacchetta, P., van Wincoop, E., 2005. A theory of the currency denomination of international trade. Journal of International Economics, 67, 295-319.

[9] Benati, L., 2008. Investigating inflation persistence across monetary regimes. The Quarterly Journal of Economics, 123, 1005-1060.

[10] Bils, M., Klenow, P., 2004. Some evidence on the importance of sticky prices. Journal of Political Economy, 112, 947-85.

[11] Calvo, G., 1983. Staggered prices in a utility maximizing framework. Journal of Monetary Economics, $12,383-398$.

[12] Calvo, G., Reinhart, C., 2002. Fear of floating. The Quarterly Journal of Economics, 117, 379-408.

[13] Campa, M., Goldberg, L., 2005. Exchange rate pass-through into import prices. Review of Economics and Statistics, 87, 679-690. 
[14] Canzoneri, M., Cumby, R., Diba, B., López-Salido, D., 2008. Monetary aggregates and liquidity in a Neo-Wicksellian framework. Journal of Money, Credit and Banking, 40, 1667-1698.

[15] Choudhary, A., Naeem, S., Faheem, A., Hanif, N., Pasha, F., 2011. Formal sector price discoveries: preliminary results from a developing country. State Bank of Pakistan Working Papers Series, No. 42.

[16] Christiano, L., Eichenbaum, M., Evans, C., 2005. Nominal rigidities and the dynamic effects of a shock to monetary policy. Journal of Political Economy, 113, 1-45.

[17] Cogley, T., Primiceri, G., Sargent, T., 2010. Inflation-gap persistence in the US. American Economic Journal: Macroeconomics, 2, 43-69.

[18] Cogley, T., Sargent, T., 2005. Drift and volatilities: monetary policies and outcomes in the post WWII U.S. Review of Economic Dynamics, 8, 262-302.

[19] Cogley, T., Sbordone, A., 2008. Trend inflation, indexation, and inflation persistence in the New Keynesian Phillips Curve. American Economic Review, 98, 2101-2126.

[20] Cole, H., Obstfeld, M., 1991. Commodity trade and international risk sharing: how much do financial markets matter? Journal of Monetary Economics, 28, 3-24.

[21] Collard, F., Juillard, M., 2009. Stochastic simulations with DYNARE. A practical guide. CEPREMAP (http://www.dynare.org/documentation-and-support/tutorial/guide.pdf/view). Accessed on 27 September, 2014.

[22] Collard, F., Juillard, M., 2001. A higher-order Taylor expansion approach to simulation of stochastic forward-looking models and application to a nonlinear Phillips curve. Computational Economics, 17, $125-139$.

[23] Devereux, M., Engel, C., 2001. Endogenous currency of price setting in a dynamic open economy model. NBER Working Paper No. 8559.

[24] Devereux, M., Engel, C., Storgaard, P., 2004. Endogenous exchange rate pass-through when nominal prices are set in advance. Journal of International Economics, 63, 263-291.

[25] Devereux, M., Engel, C., 2007. Expenditure switching versus real exchange rate stabilization: Competing objectives for exchange rate policy. Journal of Monetary Economics, 54, 2346-2374.

[26] Devereux, M., Yetman, J., 2010. Price adjustment and exchange rate pass-through. Journal of International Money and Finance, 29, 181-200.

[27] Dias, D., Marques, C.R., 2010. Using mean reversion as a measure of persistence. Economic Modelling, $27,262-273$.

[28] Engel, C., 1993. Real exchange rates and relative prices. Journal of Monetary Economics, 32, 35-50.

[29] Engel, C., Rogers, J., 1996. How wide is the border? American Economic Review, 86, 1112-1125. 
[30] European Central Bank, 2014. The international role of the Euro.

[31] Flamini, A., 2007. Inflation targeting and exchange rate pass-through. Journal of International Money and Finance, 26, 1113-1150.

[32] Fuentes, M., 2007. Pass-through to import prices: evidence from developing countries. Instituto de Economía Pontificia Universidad Católica de Chile, Working Paper No. 320.

[33] Fuhrer, J., Moore., G., 1995. Inflation persistence. The Quarterly Journal of Economics, 110, 127-159.

[34] Gali, J., Gertler, M., 1999. Inflation dynamics: A structural econometric analysis. Journal of Monetary Economics, 44, 195-222.

[35] Goldberg, L., Tille, C., 2006. The Internationalization of the dollar and trade balance adjustment. Federal Reserve Bank of New York Staff Reports No. 255.

[36] Gopinath, G., Itskhoki, O., Rigobon, R., 2010. Currency choice and exchange rate pass-through. American Economic Review, 100, 304-336.

[37] Gouvea, S., 2007. Price rigidity in Brazil: evidence from CPI micro data. Banco Central do Brasil Working Paper Series, No. 143.

[38] Granato, J., Lo, M., Wong, M.C.S., 2006. Testing monetary policy intentions in open economies. Southern Economic Journal, 72, 730-746.

[39] Hansen, B., 1999. The grid bootstrap and the Autoregressive model. The Review of Economics and Statistics, 81 (4), 594-607.

[40] Kilian, L., Manganelli, S., 2007. Quantifying the risk of deflation. Journal of Money, Credit and Banking, 39, 561-90.

[41] Kilian, L., Manganelli, S., 2008. The central banker as a risk manager: estimating the Federal Reserve's preferences under Greenspan. Journal of Money, Credit and Banking, 40, 1103-29.

[42] Kovanen, A, 2006. Why do prices in Sierra Leone change so often? A case study using micro-level price data. IMF Working Paper WP/06/53.

[43] Kuralbayeva, K., 2011. Inflation persistence and exchange rate regime: Implications for dynamic adjustment to shocks in a small open economy. Journal of Macroeconomics, 33, 193-205.

[44] Levin, A., Piger, J., 2006. Is inflation persistence intrinsic in industrial economies? Working Paper, Federal Reserve Board.

[45] Lindé, J., Nessen, M., Söderström, U., 2009. Monetary policy in an estimated open-economy model with imperfect pass-through. International Journal of Finance and Economics, 14, 301-333. 
[46] Marques, C., 2004. Inflation persistence: facts or artifacts? European Central Bank Working Paper No. 371.

[47] Medina, J. P., Rappoport, D., Soto, C., 2007. Dynamics of price adjustments: evidence from micro level data for Chile. Central Bank of Chile Working Papers Series, No. 432.

[48] Mumtaz, H., Oomen, O.,Wang, J., 2006. Exchange rate pass-through into U.K. import prices. The Bank of England Working paper No 312.

[49] Nobay, A., Paya, I., Peel, D., 2010. Inflation dynamics in the US: global but not local mean reversion. Journal of Money, Credit and Banking, 42, 135-150.

[50] Obstfeld, M., Rogoff, K., 2000. The six major puzzles in international macroeconomics: is there a common cause? NBER Macroeconomics Annual, 15, 339-412.

[51] Obstfeld, M., Rogoff, K., 1995. Exchange rate dynamics redux. Journal of Political Economy, 103, 624-60.

[52] Orphanides, A., Wilcox, D., 2002. The opportunistic approach to disinflation. International Finance, $5,47-71$.

[53] Paya, I., Duarte, A., Holden, K., 2007. On the relationship between inflation persistence and temporal aggregation. Journal of Money, Credit and Banking, 39, 1521-1531.

[54] Perron, P., 1990. Testing for a unit root in a time series with a changing mean. Jounral of Business and Economic Statistics, 8, 153-162.

[55] Pivetta, F., Reis, R., 2007. The persistence of inflation in the United States. Journal of Economic Dynamics and Control, 31, 1326-1358.

[56] Rhee, H., Turdaliev, N., 2012. Optimal monetary policy in a small open economy with inflation and output persistence. Economic Modelling, 29, 2533-2542.

[57] Schmitt-Grohé, S., Uribe, M., 2004. Solving dynamic general equilibrium models using a second-order approximation to the policy function. Journal of Economic Dynamics and Control, 28, 755-775.

[58] Sims, C., 2002. Comment on "Evolving Post-World War II U.S. Inflation Dynamics" in NBER Macroeconomics Annual 2001, 16, eds. Ben Bernanke and Kenneth Rogoff, 373-79. Cambridge, MA: MIT Press.

[59] Smets, F., Wouters, R., 2002. Openness, imperfect exchange rate pass-through and monetary policy. Journal of Monetary Economics, 49, 947-981.

[60] Steinsson, J., 2003. Optimal monetary policy in an economy with inflation persistence. Journal of Monetary Economics, 50, 1425-1456.

[61] Stock, J., 2001. Macro-econometrics. Journal of Econometrics, 100, 29-32. 
[62] Stock, J., 1991. Confidence intervals for the largest autoregressive root in U.S. macroeconomic time series. Journal of Monetary Economics, 28, 435-459.

[63] Taylor, J., 2000. Low inflation, pass-through, and the pricing power of firms. European Economic Review, 44, 1389-1408. 


\section{A Calibration and business cycle properties}

Unless otherwise specified, all business cycle data come from the IMF's International Financial Statistics database and cover the 1975Q2-2009Q4 period. Individual variables come from the U.S. data, whereas cross-country correlations are calculated using the U.S. and the UK variables.

$P, P^{*}$ : Consumer prices, all items (city average). Series ID: $64 \ldots \mathrm{ZF}$.

$Y, Y^{*}$ : Real gross domestic product, calculated as nominal GDP (series ID: 99B.CZF) deflated by the level of consumer prices, $P$ or $P^{*}$.

$C, C^{*}$ : Real consumption, calculated as nominal private final consumption expenditure (series ID: 96F.CZF) deflated by the level of consumer prices, $P$ or $P^{*}$.

I: Real investment, calculated as nominal gross fixed capital formation (series ID: 93E.CZF) deflated by $P$.

$Q$ : Real exchange rate (between the U.S. and the UK), computed as the nominal exchange rate (series ID: ..AG.ZF) times the relative price ratio $P^{*} / P$.

$C A$ : U.S. current account. Source: Bureau of Economic Analysis, Table 1.1, U.S. International Transactions. 


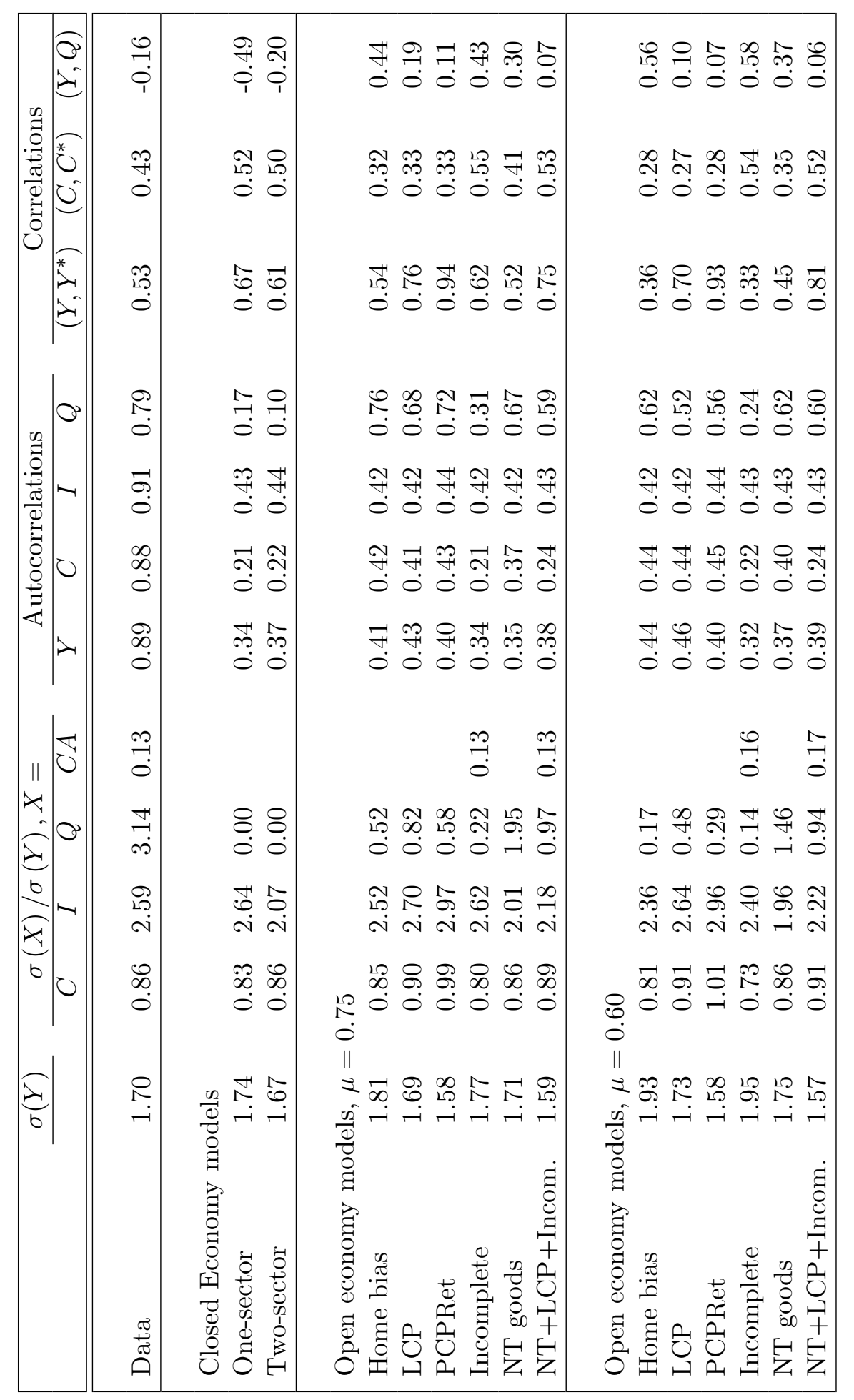

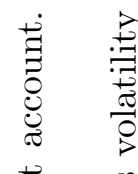

范

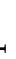

$\rightarrow$

형

ह

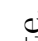

苑

ํㅠㅇ

๘ี

ن 苞 㲔

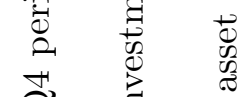

芩

กิ .ำ

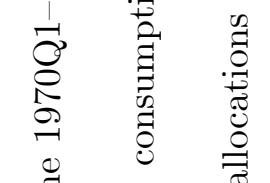

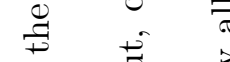

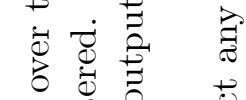

कै

.

के

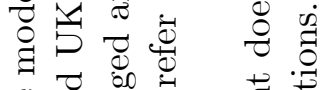

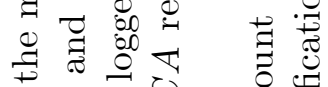

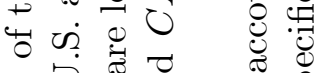

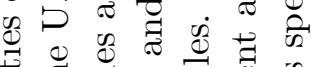

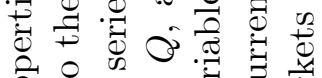

웅요

పे,

0

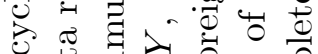

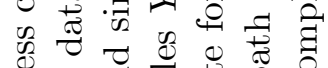

串

ज雨

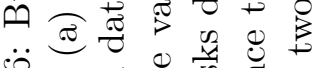

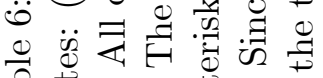

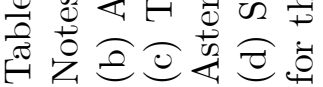

